\title{
Cognitions of \\ Restrained and Unrestrained Eaters \\ under Fasting and Nonfasting \\ Conditions
}

\author{
A thesis \\ submitted in partial fulfilment \\ of the requirements for the Degree of \\ Master of Arts in Psychology \\ in the \\ University of Canterbury \\ by
}

Catherine A. Hickford

University of Canterbury

1996 


\section{CONTENTS}

PAGE

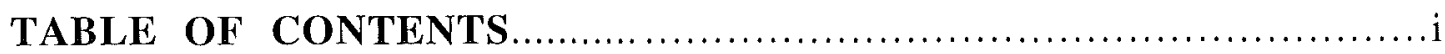

LIST OF FIGURES AND TABLES .................................. iii

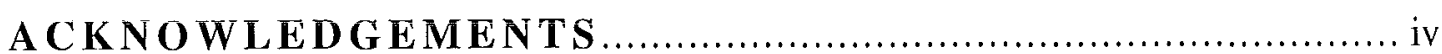

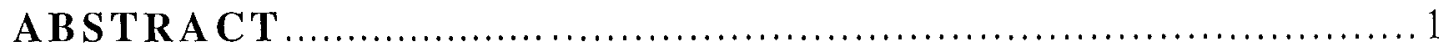

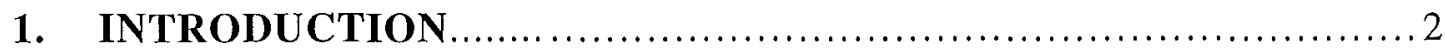

1.1. Dieting and Restraint ........................................... 3

Definitions................................................. 3

Prevelance of Dietary Restraint..................................... 3

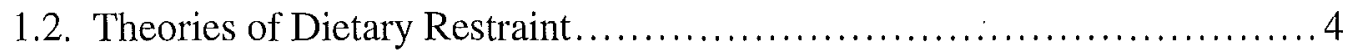

1.3. The Cognitions of Restrained Eaters, Unrestrained Eaters, and Women with Eating Disorders........................................ 7

Unrestrained vs. Eating Disordered.................................. 7

Restrained vs. Eating Disordered .............................. 8

Restrained vs. Unrestrained .........................................10

1.4. The Measurement of Cognitions .................................... 18

1.5. Analysing Thought Transcripts .................................20

1.6. Aims of the Present Study ........................................22

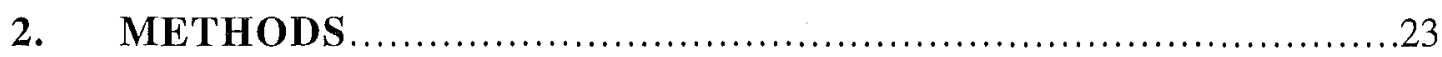

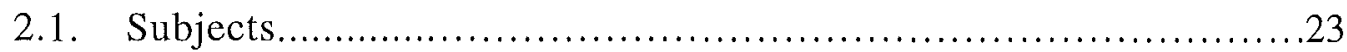

2.3. Instruments...............................................24

Quantitative measures ............................................24

Qualitative measure : Grounded analysis................................25

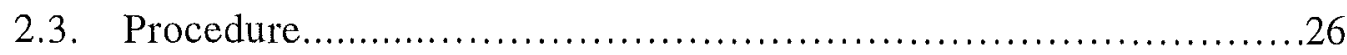




\section{CONTENTS (continued)}

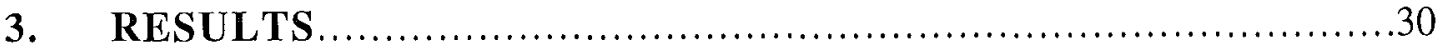

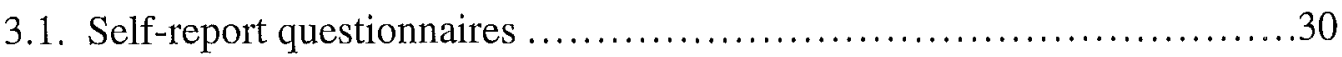

3.2. Analyses of the Thought Transcripts............................... 31

Step One : Grounded Analysis : Category Formation ...................31

Step Two : Quantitative Analysis .................................38

A) Percentage of Thoughts comparisons .....................38

Total raw number of thoughts ........................38

Major category percentages .........................39

Subcategories....................................40

B) Nature of Thoughts comparisons ......................44

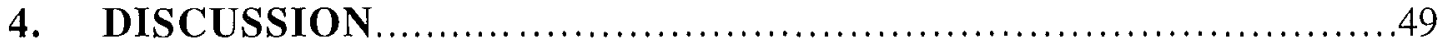

4.1. Conclusions and Recommendations for Future Research ................54

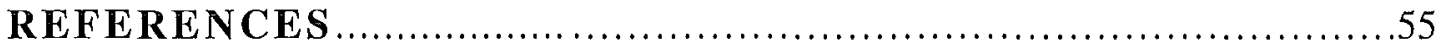

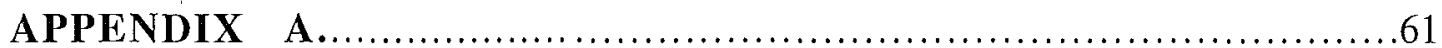

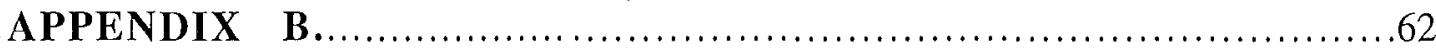

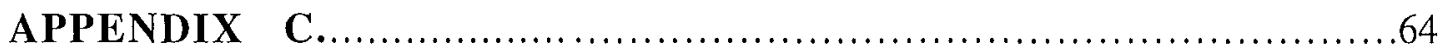

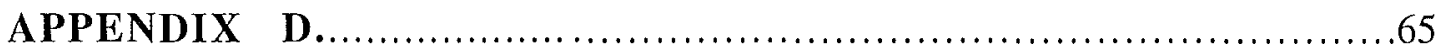




\section{LIST OF FIGURES AND TABLES}

FIGURE

PAGE

1. Percentage of Thoughts in the Major Categories ....................... 39

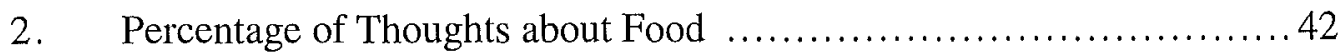

3. Percentage of Thoughts about Others................................. 44

4. Mean ratings on the dimension "Evaluation of Food" ..................46

5. Mean ratings on the dimension "Self-Evaluation Personality and Behaviour" ................................. 47

TABLE PAGE

1. Summary of Studies involving Cognitions and Dietary Restraint....... 15

2. Characteristics of the Restrained and Unrestrained Subjects..............23

3. Means and Standard Deviations on EDI subscales .................... 31

4. Categories obtained through Grounded Analysis ..................... 33

5. Percentage of Thoughts in the Major categories....................... 40

6. Means and Standard Deviations of the Percentage of Thoughts in each Subcategory................................................ 41

7. Means and Standard Deviations on Dimensionalised Subscales.......... 45 


\section{ACKNOWLEDGEMENTS}

I would like to thank my supervisors Dr Cynthia Bulik and Dr Tony Ward, whose encouragement and expertise has been much appreciated throughout this project.

In addition, I would also like to thank Rachael Lawson, Dr Steve Hudson, and Ted Beer for their assistance, my friends and family for their support, and an extra special thanks to Graham for all of your help and love along the way. 


\begin{abstract}
It has recently been suggested that the cognitions of unrestrained eaters and those of individuals with eating disorders are at opposing ends of a continuum, with restrained eaters occupying an intermediate position. The present study explored the everyday cognitions of 10 restrained and 10 unrestrained eaters under fasting and nonfasting conditions using a random thought-sampling technique. Grounded analysis of the thought transcripts yielded a number of categories related to food, self, and others. The results revealed no differences between restrained and unrestrained eaters in terms of their relative percentages of thoughts about food and self. Differences were evident, however, in the nature of their cognitions. Unrestrained eaters were more critical of their own personality and behaviour under the fasting condition than under the nonfasting condition, whereas the restrained eaters' evaluations of themselves did not differ across conditions. Under the nonfasting condition, however, restrained eaters exhibited a more negative self-concept than the unrestrained eaters. Both groups had a significantly higher percentage of thoughts about food under the fasting condition and restrained eaters made higher evaluations of food overall compared to the unrestrained eaters. The results of the present study are consistent with other studies that have used thought-sampling and think-aloud techniques, however they contrast with studies that have employed self-report questionnaires. Hence, the emphasis on self-report questionnaires in both clinical and research contexts may fail to capture important cognitive data. Further, the results from this study suggest that the continuum hypothesis may hold only when it is the nature of cognitions, not their frequency, that is considered.
\end{abstract}




\section{INTRODUCTION}

Recent clinical interest in the psychological characteristics of restrained eaters stems from findings that dietary restraint often precedes the onset of eating disorders (Wooley \& Wooley, 1985; Mitchell, Hatsukami, Eckert \& Pyle, 1985; Lacey, Coker, \& Birtchnell, 1986). The clinical and experimental literatures indicate that dieting is associated with and increases the likelihood of subsequent binge eating (Polivy \& Herman, 1985). Up to $74 \%$ of women with bulimia nervosa begin bingeing and purging following unsuccessful attempts to maintain low carbohydrate diets (Lacey et al., 1986). Hence, it has been suggested that dietary restraint, rather than bulimia nervosa and anorexia nervosa, should be the target of treatment (Polivy \& Herman, 1985, 1992).

Cognitive theories implicate cognitive dysfunction in the genesis and maintenance of eating disorders and have strongly influenced the current emphasis of cognitive treatment for women with eating disorders (Fairburn, 1985; Polivy \& Herman, 1985). The importance of cognition in the eating disorders and the hypothesised link between dietary restraint and the eating disorders have led researchers to explore the cognitions of restrained eaters. It has been proposed that the cognitive characteristics of restrained eaters lie on a continuum between those of unrestrained eaters and individuals with eating disorders (Ruderman, 1986a; Thompson, Berg \& Shatford, 1987; Cooper \& Fairburn, 1992). To date, however, only a handful of studies have tested this hypothesis. The present study explored the everyday cognitions of restrained and unrestrained eaters in order to investigate whether there were differences in the frequency or nature of their thoughts. 


\subsection{Dieting and Restraint}

\section{Definition}

Dieting has been defined as involving "the replacement of internally regulated eating with cognitively determined, planned diet-approved eating with the goal of weight reduction (Polivy \& Herman, 1995). Restrained eating has been similarly defined as " the tendency to restrict food intake consciously in order to maintain body weight or to promote weight loss" (Westenhoeffer, 1991). Thus, there is no clear distinction between these terms and they are often used interchangeably in the literature. Despite the development of various psychometric measures including Herman \& Mack's (1975) Restraint Scale, and the Dutch Eating Behaviour Questionnaire (DEBQ; van Strien, Frijters, Bergers, \& Defares, 1986), confusion is still evident in the literature. For the purposes of the present paper restrained eaters were operationally defined as individuals who reported that they were currently dieting and had a high restraint score ( $>8)$ on Herman \& Mack's (1975) Restraint Scale. See Heatherton, Herman, Polivy, King \& McGree (1988) and Ruderman (1986b) for further discussion of the issues involved in the measurement of restraint.

\section{The Prevalence of Dietary Restraint}

Studies have consistently found a high prevalence of dieting among the general population over the last 30 years. In the 1960's and 1970's significant proportions of normal adolescent samples were dieting to lose weight (Dwyer, Feldman \& Mayer, 1967; Nylander, 1971). More recently, Rosen \& Gross (1987) surveyed over a thousand adolescents of average weight and found that $63 \%$ of the females and $16 \%$ of the males were dieting to lose weight. Leon, Perry, Mangelsdorf, \& Tell (1989) found that 25\% of 256 ninth grade female students were currently dieting to lose weight and $73 \%$ had attempted to lose weight in their life-times. 
Studies have also revealed that considerable proportions of the normal adult population restrict their eating. Rand \& Kuldau (1991) studied the prevalence of restrained eating in a random sample of 2115 adults and found that overall 16\% engaged in restrained eating. Restrained eating was identified in a significantly greater percentage of women than men $(20.7 \%: 8.9 \%)$. Women aged $18-24$ and $25-34$ yrs had the highest percentage of restrained eaters $(31 \%, 29 \%)$. The majority of restrained eaters reported that they were currently dieting (81\%). Serdula, Williamson, Anda, Levy, Heaton, \& Byers (1994) carried out a multi-state telephone survey and found that approximately $38 \%$ of females and $24 \%$ of males were trying to lose weight at that time. The methods used to lose weight included appropriate caloric restriction combined with physical exercise (52\% females, $47 \%$ males), counting calories $(24 \%, 14 \%)$, organised weight loss programs $(10 \%, 3 \%)$, taking special supplements $(10 \%, 7 \%)$ taking diet pills $(4 \%, 2 \%)$, and fasting $(5 \%, 5 \%)$.

In sum, dieting behaviour, particularly among women, is prevalent among the normal population so much so that repeated attempts at weight loss have been described as "the norm" (Polivy \& Herman, 1987).

\subsection{Theories of Restraint}

Herman \& Polivy (1984) applied a boundary model to the regulation of eating to explain how physiological and non physiological phenomena determine eating patterns. They proposed that an organism's eating behaviour is maintained between a biological range of hunger and satiety. Within this range, the organism experiences physical comfort. If the organism's food intake places it outside this range, physical discomfort is experienced and action is usually undertaken to escape the biologically aversive state and return to a point within the hunger-satiety boundaries, "the zone of biological indifference" (Herman \& Polivy, 1984, p. 144). Herman \& Polivy proposed that non physiological factors, such as cognitive and social pressures, also play a role in the regulation of eating. Although non physiological factors can influence the organism's eating behaviour at any time, their effects are most powerful when the organism is within the range of biological indifference. 
Herman \& Polivy (1984) suggested that dieters have lower hunger boundaries and higher satiety boundaries than non-dieters, resulting in less physiological control. They suggest that an additional cognitive diet boundary, set according to the dieter's beliefs about food consumption in a specific situation, regulates the dieter's eating.

A number of social factors have been implicated in the genesis of dietary restriction. Social pressures to be thin come from a number of sources including families, communities, and societies (Sobal, 1995). Families influence their member's weight and body shape by providing a family culture which reinforces acceptable body weights and shapes, eating practices, and activities. Family values are themselves influenced by the values of the communities, societies and cultures in which they are embedded.

Modern Western culture places enormous pressure on women to be thin. The messages women receive from the media and well-meaning friends and family members is that any body shape that is not thin can not and need not be tolerated. To be fat is to be lazy, unattractive and lacking in self-discipline and self-control. To be thin is to be the opposite : healthy, beautiful, successful and powerful (Wilfley \& Rodin, 1995). The goal of obtaining the perfect body is driven by two beliefs (Brownell, 1991), i) the ideal body can be achieved as bodies are infinitely malleable and ii) having the ideal body will reap enormous personal benefits including higher social status, happiness, and sexual attractiveness. For most women, however, no amount of exercise or dietary restraint will result in the perfect body as the extent to which changes in body shape and weight are attainable is constrained by genetic factors (Wilfley \& Rodin, 1995).

Psychological factors that have been found to be associated with dietary restraint include low self-esteem (Polivy, Heatherton \& Herman, (1988); depression (Eldredge, Wilson, \& Whaley, 1990); maladjustment (Ruderman, 1985); and neuroticism (Herman \& Polivy, 1980). However, the direction of causality is not clearly established. It is likely that personality and adjustment factors play a role in the decision of some individuals to diet. For others, these characteristics may result from a combination of the physiological effects of dieting and the failure to adhere to these self-imposed restrictions. 
Heatherton \& Polivy (1992) have outlined a spiral model of how social and psychological factors can determine the onset and maintenance of dietary restraint in some individuals. They propose that at the onset of adolescence individuals become aware of the ideal body shape prescribed by their culture and make a comparison between their own bodies and that ideal. Those who perceive a discrepancy between the two experience body-dissatisfaction and attempt to change their bodies to be more like the ideal, typically through dieting. Heatherton \& Polivy propose that adolescents with low self-esteem are at a greater risk of beginning dieting.

As most dieting attempts fail to produce lasting weight reduction (Polivy \& Herman, 1985), people are more than likely to experience failure and individuals who attribute this failure to personal deficiencies will continue to diet using more extreme methods to bring about weight loss. The physiological consequences of food restriction combined with the disappointment of past and present failures to obtain the ideal body result in organic stress, lowered self-esteem and increasing negative affect which in turn lead to the increasing likelihood of dietary failure. The unsuccessful dieter is easily trapped in a downward spiral and those unable to break free of the cycle may ultimately develop a pathological eating disorder ( Herman \& Polivy, 1992).

The factors that place restrained eaters at risk of developing an eating disorder are unknown but the growing evidence that cognitive disturbances play a role in the genesis and maintenance of eating disorders suggests that research into the cognitions of restrained eaters will have an important role to play in determining what the key factors are. 


\subsection{The Cognitions of Restrained Eaters, Unrestrained Eaters, and Women with Eating Disorders}

Relatively few studies have investigated the cognitions of restrained eaters. Of these some have only compared the cognitions of restrained eaters with unrestrained eaters while others have also included an eating disordered sample. These latter studies reveal a number of significant differences between unrestrained eaters and those with an eating disorder (see Table 1. for a summary of the relevant studies).

\section{Unrestrained Eaters vs. Women with Eating Disorders}

Women with eating disorders have been consistently found to be more preoccupied with eating-, food- and weight-related concerns (e.g. Fairburn, Cooper, Cooper, McKenna \& Anastasiades, 1990; King, Herman \& Polivy, 1991), to have higher frequencies of negative and depressogenic thinking (e.g. Zotter \& Crowther, 1991; Cooper, Clark \& Fairburn, 1993), to experience a greater proportion of guilt-related thoughts (Clark, Feldman \& Channon, 1989) and to have more control-related thoughts (Dykens \& Gerrard, 1985; Butow, Beumont, \& Touyz, 1993) than unrestrained eaters.

There is some evidence that the relationship between dysfunctional cognitions and eating-disordered symptomatology may be mediated by depressive symptoms (e.g. Cooper et al, 1993; Dykens \& Gerrard, 1985). However, Poulakis \& Wertheim (1993) found that dysfunctional cognitions were also significantly associated with bulimic tendencies irrespective of depressive symptomatology. Similarly women with anorexia nervosa have been shown to exhibit a greater frequency of irrational cognitions (Steiger, Goldstein, Mongrain, \& van der Feen, 1989) and dichotomous thinking compared with non-eating disordered women (Butow, et al., 1993). 


\section{Restrained Eaters vs. Women with Eating Disorders}

Only a small number of studies have compared the cognitions of restrained eaters and eating-disordered individuals and these studies have typically produced conflicting findings (See Table 1). This makes it difficult to draw any firm conclusions although it does appear that generally, there are fewer differences between the cognitions of these two groups than between eating-disordered individuals and unrestrained eaters .

Butow et al.(1993) found that women with eating disorders were more concerned about their weight than restrained eaters. This result was further clarified by Cooper \& Fairburn (1992) who found that whereas women with bulimia nervosa had more concerns about their weight and appearance than restrained eaters, they did not differ from women with anorexia nervosa with respect to weight and appearance cognitions. Butow et al. found no differences between restrained eaters and women with eating disorders in their cognitions about eating whereas Cooper \& Fairburn found that restrained eaters had significantly fewer negative thoughts related to eating than women with anorexia but did not differ from women with bulimia nervosa regarding eatingrelated cognitions.

The distinction between restrained eaters and eating disordered women with respect to self-related cognitions is complex and unclear. While Dykens \& Gerrard (1985) found that repeat dieters had a significantly higher physical self-concept than women with bulimia nervosa there were no differences on self-report measures of self-acceptance and self-concepts relating to the domains of behavior, moral-ethical, and personal attributes. Similarly Butow et al. (1993) found that both women with bulimia nervosa and women with anorexia nervosa appeared to have a more negative self-image than women who dieted, yet these three groups did not differ in the way in which they compared themselves to others in terms of weight, attractiveness, confidence, goodness, and extroversion. 
The only study to compare the personality styles of repeat dieters and women with eating disorders (Dykens \& Gerrard, 1985) found that women with bulimia nervosa had significantly higher scores than repeat dieters on the Hypochondriasis, Depression, Hysteria, Psychopathic Deviate, Paranoia, and Schizophrenia scales of the Minnesota Multiphasic Personality Inventory (MMPI). Scores on the Psychasthenia, and Hypomania scales did not differ between the two groups. It should be noted however that all of the subjects were within the normal range.

Conflicting findings are also evident with respect to control-related cognitions. Dykens \& Gerrard (1985) found no differences between repeat dieters and women with bulimia nervosa on the self-reported measures of external locus of control whereas Butow et al (1993) found that subjects with bulimia employed the construct "control" more frequently than dieters.

The results of studies that have compared the affective tone of cognitions in restrained eaters and women with eating disorders differ according to the measurement technique employed. Women with bulimia nervosa have been found to experience a significantly greater proportion of negative affective in vivo cognitions than repeat dieters in their day-to-day lives (Zotter \& Crowther, 1991) whereas Dykens \& Gerrard (1985) found no difference between women with bulimia nervosa and restrained eaters in their scores on the Depression subscale of the MMPI.

It is unclear whether the cognitions of women with eating disorders have a higher degree of dysfunction than restrained eaters. Butow et al's (1993) study indicated that the cognitions of women with eating disorders were more irrational than those of repeat dieters whereas Zotter \& Crowther (1991) found no differences in the frequency of distorted and dichotomous cognitions with both groups experiencing very few distorted and dichotomous cognitions in their day-to-day lives. 
It appears therefore that while the cognitions of women with eating disorders differ from those of unrestrained eaters in a number of important ways, the relationship between the cognitions of women with eating disorders and those of restrained eaters is less distinct. This finding is consistent with the continuum hypothesis (e.g. Ruderman, 1986a) which proposes that the cognitions of restrained eaters are more similar to the cognitions of women with eating disorders than are those of unrestrained eaters. In order to test the continuum hypothesis further it is necessary to examine the relationship between the cognitions of restrained and unrestrained eaters.

\section{Restrained vs. Unrestrained Eaters}

Studies that have compared the cognitions of restrained and unrestrained eaters are summarised in Table 1. In general, studies that have measured the frequency of food-, weight- and appearance-related cognitions have found no differences between restrained and unrestrained eaters. Jansen et al. (1988) examined the concurrent thoughts of restrained and unrestrained eaters during a disinhibitive challenge using a think-aloud technique and self-report questionnaires. They found no differences between restrained and unrestrained eaters' frequencies of thoughts about food, weight or appearance.

A study employing repertory grids (requiring the subjects to state the most important difference between word-pairs representing typically difficult situations involving eating, self-images and significant others) found that restrained and unrestrained eaters did not differ in the frequency of their use of food/weight/appearance constructs (Butow et al., 1993). Zotter \& Crowther (1991) found that repeat dieters (subjects who dieted two or more times during the past year, were dissatisfied with their current weight but exhibited no eating-disordered symptomatology) did not differ from non-eating-disordered controls (subjects who reported weight-satisfaction, maintenance of a stable weight and denied dieting and bulimic symptomatology in the past year) in their relative proportions of everyday cognitions about eating/weight-related issues. 
Finally, Cooper \& Fairburn (1992) found no differences in the frequency of restrained and unrestrained eaters' concurrent verbalisations about food, weight, and appearance during three tasks in which the subjects were required to weigh themselves, look at themselves in a full-length mirror, and eat a chocolate mint. Restrained eaters' responses to a self-report questionnaire, however, indicated that they had spent more time thinking about food/ weight/ appearance issues than unrestrained eaters during the weighing task. This study contained two groups of restrained eaters : women who had been making a serious attempt to lose weight for at least the four preceding weeks (normal dieters), and women who had been making a serious attempt to lose weight in at least the past 4 weeks and who had a history of, or currently evidenced, some characteristics of anorexia nervosa or bulimia nervosa (symptomatic dieters). No significant differences were found between these two groups.

By contrast, a study in which subjects were asked to reproduce a previously read essay containing items relating to a woman's eating, food and weight-related behaviours, age-related activities and sewing and fashion-related activities found that restrained eaters displayed significantly better relative recall for the weight/food items compared with the unrestrained eaters (King, Herman, \& Polivy, 1991). Following the recall exercise subjects were asked to list noticeable aspects of their own and others' physical appearance, things they spent the most time thinking about, and types of activities they most enjoyed. Significant positive correlations were found between the level of dietary restraint and the frequency of weight- and food-related words that were reported. Unfortunately, the measure used to determine restraint levels was not documented.

The differences between King et al.'s finding and those of the other studies can partially be explained in terms of differences in the constructs being measured. King et al. (1991) measured the relative accessibility of food, weight, and appearance cognitions during a recall task whereas the other studies measured the frequency of spontaneouslyelicited cognitions about food, weight and appearance. King et al.'s finding that restrained eaters described themselves more often in terms of food, weight and appearance constructs than unrestrained eaters was possibly biased by the previous recall task. Thus the research on food-related cognitions suggests that there are few differences between restrained and unrestrained eaters in the naturally-occurring frequencies of these thoughts. 
Very few studies have investigated whether there are differences between restrained eaters and women with eating disorders in terms of the nature of their thoughts about food. The relationship between the level of restraint and the degree of hunger expressed during a disinhibitory challenge was studied by Ogden \& Wardle (1991). They found that high restraint subjects reported experiencing more intense hunger compared to low restraint subjects. In addition, a study exploring the concept of guilt related to eating, Dewberry \& Ussher (1994) found that high-restraint was correlated with greater guilt about a variety of eating situations.

The differences between the self-concepts of restrained and unrestrained eaters have received little attention. While it has been found that women who repeatedly diet exhibit a lower self-acceptance, lower self-concepts of their behaviours, attitudes and personal attributes and a lower physical esteem than non-bulimic, non-dieting controls (Dykens \& Gerrard, 1985) another study found no differences in the way restrained and unrestrained eaters described themselves using a repertory grid (Butow et al., 1993).

Studies have produced differing results regarding the affective tone of restrained and unrestrained eaters' cognitions. The conflicting findings are likely to be due to the differences in the methodologies employed to measure cognitions. Studies using selfreport questionnaires to measure levels of depressogenic cognitions (Ogden \& Wardle, 1991; Dykens \& Gerrard, 1985) have found that restrained eaters exhibit more depressogenic cognitions than unrestrained eaters whereas studies using thoughtsampling and think-aloud techniques (Zotter \& Crowther, 1991; Cooper \& Fairburn, 1992) have found that restrained and unrestrained eaters do not differ in they frequency of their negative affective cognitions. 
There is some evidence that restrained eaters exhibit a higher degree of irrationality (unrelated to an overall tendency to distort information) than unrestrained eaters (Ruderman, 1985). Further, Dewberry \& Ussher (1994) found evidence to suggest that restrained eaters tend to exhibit distorted body perceptions. Estimations of own body weight by high-restrainers were significantly less accurate than the estimates of low-restrainers, with high-restrainers tending to overestimate their own weight. However, other studies have found no differences between restrained and unrestrained eaters on measures of irrationality using self-report questionnaires (Jansen et al., 1988) and in vivo thought-sampling (Zotter \& Crowther, 1991).

Finally, restrained eaters have been found to exhibit more control-related thoughts than unrestrained eaters under both normal and dietary violation conditions (Dykens \& Gerrard, 1985; Jansen et al., 1988; French, 1992; Ogden \& Wardle, 1991). The nature of these control-related thoughts is unclear. Some studies have found that restrained eaters have a relatively higher external locus of control (Dykens \& Gerrard, 1985) and experience a greater frequency of cognitions of perceived uncontrollability (Jansen et al., 1988) than unrestrained eaters. Other studies suggest that restrained eaters appear to believe they can control their eating. For example, restrained eaters entertain a greater number of intentions for the future control of their eating than unrestrained eaters (French, 1992), and exhibit a greater frequency of active self-control thoughts during disinhibitory challenges [active self-control cognitions are cognitions that challenge or actively defy dietary constraints as opposed to passive cognitions which are thoughts surrendering to the drive to eat (Ogden \& Wardle, 1991)]. It should also be noted that whereas Jansen et al.'s study revealed that restrained eaters indicated greater perceived uncontrollability than unrestrained eaters during a disinhibitive challenge on a selfreport questionnaire, this difference did not emerge from their "think-aloud" data. 
In general previous research indicates no consistent differences in the frequencies of thoughts about food, weight, appearance, self-concept, and the level of dysfunction of cognitions of restrained and unrestrained eaters. It is, however, possible that the lack of findings may be due to inadequate differences between restraint groups. A number of the above studies assigned subjects to a restrained group or unrestrained group on the basis of a median split in scores on a restraint measure (e.g. Jansen et al., 1988; Ogden \& Wardle, 1991) while others distinguished between restrained and unrestrained subjects according to independent operational definitions (e.g. Zotter \& Crowther, 1991; Cooper \& Fairburn, 1992). Some of these studies have, however, found differences in the quality or nature of thoughts about food, weight and appearance of restrained and unrestrained eaters suggesting that adequate differences between levels of restraint were obtained.

Overall, a review of previous research suggests that the cognitions of restrained eaters are neither predominantly different from the cognitions of eating disordered subjects or the cognitions of unrestrained eaters. This finding supports the theory that the cognitions of restrained eaters occupy an intermediate position on a continuum between the cognitions of eating disordered individuals and unrestrained eaters (Cooper \& Fairburn, 1992). It is difficult to draw firm conclusions because of the small number of studies that have been carried out in the area of restraint and the different procedures employed to measure and compare cognitions. It has been suggested that each procedure yields a different type of data (Blackwell, Galassi, Galassi \& Watson, 1985). Therefore, a brief summary of the issues involved in reliably measuring cognitions is required. 
Table 1.

Summary of Studies Involving Cognitions and Dietary Restraint.

Significant findings

\begin{tabular}{|c|c|c|c|c|c|}
\hline \multirow[b]{2}{*}{ Authors } & \multirow[b]{2}{*}{$\begin{array}{l}\text { Type of } \\
\text { subject (n) }\end{array}$} & \multirow[b]{2}{*}{ Measures } & \\
\hline & & & ED vs URE & $\mathrm{ED}$ vs $\mathrm{RE}$ & RE vs URE \\
\hline $\begin{array}{l}\text { Zotter \& } \\
\text { Crowther } \\
(1991)\end{array}$ & $\begin{array}{l}\mathrm{BN}(16) \\
\operatorname{RD}(16) \\
\mathrm{C}(16)\end{array}$ & $\begin{array}{l}\text { SRQ } \\
\text { TS for } 2 \\
\text { days at } 30 \\
\text { minute } \\
\text { intervals }\end{array}$ & $\begin{array}{l}\mathrm{BN}>\mathrm{C} \text { : proportion } \\
\text { of eating/weight- } \\
\text { related cognitions. } \\
\mathrm{BN}>\mathrm{C}: \text { proportion } \\
\text { of negative affective } \\
\text { cognitions; } \\
\text { proportion of weight } \\
\& \text { body image } \\
\text { cognitions in the } \\
\text { eating/weight-related } \\
\text { category } \\
\mathrm{C}>\mathrm{BN} \text { : proportion } \\
\text { of food \& eating } \\
\text { thoughts in the } \\
\text { eating/weight-related } \\
\text { category }\end{array}$ & $\begin{array}{l}\text { BN }>\text { RD : proportion } \\
\text { of negative affective } \\
\text { cognitions; } \\
\text { proportion of weight } \\
\& \text { body image } \\
\text { cognitions in the } \\
\text { eating/weight-related } \\
\text { category } \\
\text { RD }>\text { BN : proportion } \\
\text { of food \& eating } \\
\text { thoughts in the } \\
\text { eating/weight-related } \\
\text { category }\end{array}$ & $\begin{array}{l}\mathrm{RD}=\mathrm{C}: \text { proportion } \\
\text { of negative affective } \\
\text { cognitions; } \\
\text { proportion of weight } \\
\& \text { body image } \\
\text { cognitions in the } \\
\text { eating/weight-related } \\
\text { category } \\
\mathrm{RD}=\mathrm{C} \text { : proportion } \\
\text { of food \& eating } \\
\text { thoughts in the } \\
\text { eating/weight-related } \\
\text { category }\end{array}$ \\
\hline $\begin{array}{l}\text { Dykens \& } \\
\text { Gerrard } \\
(1985)\end{array}$ & $\begin{array}{l}\text { BN (29) } \\
\text { RD (27) } \\
\text { C (27) }\end{array}$ & SRQ & $\begin{array}{l}\mathrm{BN}>\mathrm{C} \text { : external } \\
\text { locus of control } \\
\mathrm{C}>\mathrm{BN}: \text { self-esteem } \\
\mathrm{C}>\mathrm{BN}: \text { familial } \\
\text { esteem } \\
\mathrm{C}>\mathrm{BN} \text { : physical } \\
\text { esteem } \\
\mathrm{BN}>\mathrm{C}: \text { all MMPI } \\
\text { sub-scales }\end{array}$ & $\begin{array}{l}\mathrm{BN}=\mathrm{RD}: \text { external } \\
\text { locus of control } \\
\mathrm{BN}=\mathrm{RD}: \text { self- } \\
\text { esteem } \\
\mathrm{RD}>\mathrm{BN} \text { : physical } \\
\text { esteem } \\
\mathrm{BN}>\mathrm{RD} \text { : all MMPI } \\
\text { sub-scales except } \\
\text { Psychasthenia \& } \\
\text { Hypomania }\end{array}$ & $\begin{array}{l}\text { RD }>C \text { : external } \\
\text { locus of control } \\
\mathrm{C}>\mathrm{RD}: \text { self-esteem } \\
\mathrm{C}>\mathrm{RD} \text { : physical } \\
\text { esteem } \\
\mathrm{RD}>\mathrm{C}: \text { MMPI } \\
\text { subscales - } \\
\text { Depression \& } \\
\text { Psychopathic } \\
\text { Deviate. }\end{array}$ \\
\hline $\begin{array}{l}\text { Cooper \& } \\
\text { Fairburn } \\
(1992)\end{array}$ & $\begin{array}{l}\mathrm{AN}(12) \\
\mathrm{BN}(12) \\
\mathrm{D}(12) \\
\mathrm{D} / \mathrm{ed}(12) \\
\mathrm{C}(12)\end{array}$ & $\begin{array}{l}\text { SRQ } \\
\text { TA during } 3 \\
\text { food/weight } \\
\text {-related } \\
\text { tasks }\end{array}$ & $\begin{array}{l}E D>C: \text { frequency of } \\
\text { negative } \\
\text { eating/weight-related } \\
\text { cognitions. } \\
\text { BN }>C \text { : frequency of } \\
\text { negative cognitions } \\
\text { in the weight and } \\
\text { appearance tasks } \\
B N>C: \text { duration of } \\
\text { negative food/ } \\
\text { weight/appearance } \\
\text { cognitions in weight } \\
\text { and appearance tasks. } \\
\text { AN }>C \text { : frequency of } \\
\text { negative cognitions } \\
\text { in eating task. }\end{array}$ & $\begin{array}{l}\mathrm{BN}>\mathrm{D}+\mathrm{D} / \mathrm{ed} \text { : } \\
\text { frequency of negative } \\
\text { cognitions in the } \\
\text { weight and } \\
\text { appearance tasks } \\
\mathrm{AN}>\mathrm{D}+\mathrm{D} / \mathrm{ed} \text { : } \\
\text { frequency of negative } \\
\text { cognitions in eating } \\
\text { task. } \\
\mathrm{D} / \mathrm{ed}>\mathrm{D} \text { : similarities } \\
\text { to ED (trend) }\end{array}$ & $\begin{array}{l}\mathrm{D}=\mathrm{D} / \mathrm{ed}=\mathrm{C} \text { : } \\
\text { frequency of negative } \\
\text { cognitions in the } \\
\text { weight and } \\
\text { appearance tasks } \\
\mathrm{D}=\mathrm{D} / \mathrm{ed}=\mathrm{C} \text { : } \\
\text { frequency of negative } \\
\text { cognitions in eating } \\
\text { task. } \\
\text { No significant } \\
\text { differences between } \mathrm{D} \\
\text { and C } \\
\mathrm{D} / \mathrm{ed}>\mathrm{C}: \text { frequency } \mathrm{X} \\
\text { duration of negative } \\
\text { food/weight/appearan } \\
\text { ce cognitions in } \\
\text { weight task. } \\
\mathrm{D}=\mathrm{D} / \mathrm{ed} \text { : frequency } \\
\text { of food/ weight/ } \\
\text { appearance-related } \\
\text { cognitions between } \\
\text { that of ED \& C } \\
\text { (trend). }\end{array}$ \\
\hline
\end{tabular}

Table 1 continues. . . 
Table 1 (cont.)

Significant findings

\begin{tabular}{|c|c|c|c|c|c|}
\hline \multirow[b]{2}{*}{ Authors } & \multirow[b]{2}{*}{$\begin{array}{l}\text { Type of } \\
\text { subject (n) }\end{array}$} & \multirow[b]{2}{*}{ Measures } & \\
\hline & & & ED vs URE & $\mathrm{ED}$ vs $\mathrm{RE}$ & RE vs URE \\
\hline $\begin{array}{l}\text { Butow, } \\
\text { Beumont, } \\
\text { Touyz } \\
(1993)\end{array}$ & $\begin{array}{l}\text { AN (53) } \\
\text { BN (45) } \\
\text { RE (65) } \\
\operatorname{URE~(68)~}\end{array}$ & $\begin{array}{l}\text { Repertory } \\
\text { grids } \\
\text { SRQ }\end{array}$ & $\begin{array}{l}\text { Thoughts about } \\
\text { eating : } \\
\text { ED > URE : use } \\
\text { of"concern about } \\
\text { weight" construct } \\
\text { BN > URE : use of } \\
\text { "control" construct } \\
\text { AN > URE : use of } \\
\text { "control" contruct } \\
\text { URE > ED : use of } \\
\text { "hunger" and } \\
\text { "enjoyment of taste" } \\
\text { constructs } \\
\text { Thoughts about self } \\
\& \text { others : } \\
\text { AN > URE : use of } \\
\text { construct } \\
\text { "happiness" } \\
\text { ED > URE : use of } \\
\text { contruct "normality" } \\
\text { URE }>\text { AN : use of } \\
\text { "skills" and } \\
\text { "abilities" constructs } \\
\text { Nature of thoughts } \\
\text { about eating: } \\
\text { ED > URE : extreme } \\
\text { ratings regarding } \\
\text { control, concern } \\
\text { about weight, reward, } \\
\text { virtue, ease and } \\
\text { physical comfort. } \\
\text { Nature of thoughts } \\
\text { about self/others : } \\
\text { ED > URE : extreme } \\
\text { ratings regarding } \\
\text { concern about } \\
\text { weight. } \\
\text { AN > URE : extreme } \\
\text { ratings regarding } \\
\text { appearance, character } \\
\text { strength, self- } \\
\text { confidence and } \\
\text { extroversion } \\
\text { and }\end{array}$ & $\begin{array}{l}\text { Thoughts about } \\
\text { eating : } \\
\text { ED > RE : use } \\
\text { of"concern about } \\
\text { weight" construct } \\
\text { BN > RE : use of } \\
\text { "control" construct } \\
\text { RE = ED : use of } \\
\text { "hunger" and } \\
\text { "enjoyment of taste" } \\
\text { constructs } \\
\text { Thoughts about self } \\
\& \text { others : } \\
\text { AN = RE : use of } \\
\text { construct } \\
\text { "happiness" } \\
\text { ED }>\text { RE : use of } \\
\text { contruct "normality" } \\
\text { RE > AN : use of } \\
\text { "skills" and } \\
\text { "abilities" constructs } \\
\text { Nature of thoughts } \\
\text { about eating: } \\
\text { ED = RE : extreme } \\
\text { ratings regarding } \\
\text { control, concern } \\
\text { about weight, reward, } \\
\text { virtue, ease and } \\
\text { physical comfort. } \\
\text { Nature of thoughts } \\
\text { about selflothers : } \\
\text { ED }>\text { RE : extreme } \\
\text { ratings regarding } \\
\text { concern about } \\
\text { weight. }\end{array}$ & $\begin{array}{l}\text { Thoughts about } \\
\text { eating : } \\
\text { RE = URE : use } \\
\text { of"concern about } \\
\text { weight" construct } \\
\text { RE = URE : use of } \\
\text { "control" construct } \\
\text { RE = URE : use of } \\
\text { "hunget" and } \\
\text { "enjoyment of taste" } \\
\text { constructs } \\
\text { Thoughts about self } \\
\& \text { others : } \\
\text { RE = URE : use of } \\
\text { contruct "normality" } \\
\text { RE > AN : use of } \\
\text { "skills" and } \\
\text { "abilities" constructs } \\
\text { Nature of thoughts } \\
\text { about eating: } \\
\text { RE = URE : ratings } \\
\text { regarding control, } \\
\text { concern about } \\
\text { weight, reward, } \\
\text { virtue, ease and } \\
\text { physical comfort. } \\
\text { Nature of thoughts } \\
\text { about selffothers : } \\
\text { RE = URE : ratings } \\
\text { regarding concern } \\
\text { about weight. }\end{array}$ \\
\hline $\begin{array}{l}\text { Ruderman } \\
\text { (1985) }\end{array}$ & $\begin{array}{l}\text { high } \\
\text { RE+low } \\
\text { RE (190) }\end{array}$ & SRQ & $\mathrm{N} / \mathrm{A}$ & $\mathrm{N} / \mathrm{A}$ & $\begin{array}{l}\text { high } \mathrm{RE}>\text { low RE : } \\
\text { frequency of rigid, } \\
\text { perfectionistic } \\
\text { beliefs; frequency of } \\
\text { irrational beliefs. }\end{array}$ \\
\hline $\begin{array}{l}\text { King, } \\
\text { Herman, \& } \\
\text { Polivy } \\
\text { (1991) }\end{array}$ & $\begin{array}{l}\text { RE (35) } \\
\text { URE (31) } \\
\text { OB (24) } \\
\text { AN (6) } \\
\text { BN (4) }\end{array}$ & $\begin{array}{l}\text { Stimulus } \\
\text { essay } \\
\text { SRQ }\end{array}$ & N/A & N/A & $\begin{array}{l}\text { RE }>\text { URE : relative } \\
\text { recall for } \\
\text { weight/food-related } \\
\text { items }\end{array}$ \\
\hline
\end{tabular}


Table 1 (cont.)

\begin{tabular}{|c|c|c|c|c|c|}
\hline \multirow{2}{*}{ Authors } & \multirow{2}{*}{$\begin{array}{l}\text { Type of } \\
\text { subject (n) }\end{array}$} & \multirow{2}{*}{ Measures } & \multicolumn{3}{|c|}{ Significant findings } \\
\hline & & & ED vs URE & ED vs RE & RE vs URE \\
\hline $\begin{array}{l}\text { Jansen, } \\
\text { Merckel- } \\
\text { bach, } \\
\text { Oosterlaan } \\
\text { Tuiten, \& } \\
\text { van den } \\
\text { Hout } \\
(1988)\end{array}$ & $\begin{array}{l}\text { RE +URE } \\
(40)\end{array}$ & $\begin{array}{l}\text { SRQ } \\
\text { TA during } \\
\text { taste test }\end{array}$ & N/A & N/A & $\begin{array}{l}S R Q \\
R E=\text { URE preloaded }> \\
R E=\text { URE no preload: } \\
\text { freq. of disinhibitive } \\
\text { statements } \\
R E>\text { URE : freq. of } \\
\text { cognitions regarding } \\
\text { perceived } \\
\text { uncontrollability } \\
\text { cognitions. } \\
R E=\text { URE: irrationality } \\
T A \\
R E=U R E \text { : proportion of } \\
\text { non-food and food- } \\
\text { related categories }\end{array}$ \\
\hline $\begin{array}{l}\text { Ogden \& } \\
\text { Wardle } \\
(1991)\end{array}$ & $\begin{array}{l}\text { high RE + } \\
\text { low RE } \\
\text { (42) }\end{array}$ & $\begin{array}{l}\text { SRQ } \\
\text { Interview }\end{array}$ & N/A & N/A & $\begin{array}{l}\text { high RE > low RE : } \\
\text { levels of depression; } \\
\text { frequency of active self- } \\
\text { control cognitions; } \\
\text { higher hunger ratings. } \\
\text { Tendency to binge was } \\
\text { positively correlated } \\
\text { with high level of } \\
\text { restraint } \\
\text { Bingers > non-bingers : } \\
\text { levels of depression, } \\
\text { frequency of active self- } \\
\text { control cognitions. }\end{array}$ \\
\hline $\begin{array}{l}\text { French } \\
(1992)\end{array}$ & $\begin{array}{l}\text { RE+URE } \\
(83)\end{array}$ & $\begin{array}{l}\text { TL after } \\
\text { preload \& } \\
\text { tasting }\end{array}$ & N/A & N/A & $\begin{array}{l}\text { Preloaded RE+URE }>\text { no } \\
\text { preload RE+URE : } \\
\text { cognitions regarding } \\
\text { the need to control } \\
\text { eating in the future. } \\
\text { Level of restraint } \\
\text { positively correlated } \\
\text { with frequency of } \\
\text { control-related } \\
\text { thoughts. }\end{array}$ \\
\hline $\begin{array}{l}\text { Dewberry } \\
\text { \& Ussher } \\
\text { (1994) }\end{array}$ & $\begin{array}{l}\text { high RE + } \\
\text { low RE } \\
\text { (533) }\end{array}$ & $\begin{array}{l}\text { Structured } \\
\text { interview }\end{array}$ & N/A & N/A & $\begin{array}{l}\text { high RE > low RE : guilt } \\
\text { about eating more types } \\
\text { of food; guilt after } \\
\text { dining out; guilt about } \\
\text { large amounts of food; } \\
\text { overestimation of body } \\
\text { weight }\end{array}$ \\
\hline
\end{tabular}

\section{Abbreviations.}

$\mathrm{AN}$, anorexia nervosa (r, restricter; b, binger); $\mathrm{BN}$, bulimia nervosa (an, with history of anorexia nervosa; wan, without history of anorexia nervosa); C, control; D, dieter; RD, repeat dieter; RE, restricted eater; URE, unrestricted eater; PC, non-eating disordered psychiatric patients; ED, eating disordered. SRQ, self-report questionnaires; TA, think-aloud; TS, thought-sampling; I, interview; TL, thoughtlisting. 


\subsection{The Measurement of Cognitions}

A variety of issues may compromise the validity of the assessment of cognitions (Crutcher, 1994; Nisbett \& Wilson, 1977). It is argued that the reporting of inner experience is typically abbreviated and biased by factors such as attention and memory, and that the direct measurement of consciousness using psychometric assessments is impossible. However, other researchers claim that verbal reports can be accurate if they address conscious cognitions and the use of self-observation and self-report as methods for obtaining data are as legitimate as the processes used in the study of overt phenomena (Klinger, 1978; Ericsson \& Simon, 1980; Morris, 1981). Klinger argued that, above all, the validating process in all research involves the removal of artifacts, the replication of findings, and the utility of the data for further prediction (p. 227). He claimed that the difficulties inherent in reliably reporting inner experience can be minimised by using methods which limit the need for retaining information for long periods, and which require descriptions of individual events or verbatim reports rather than generalisations about multiple events.

The most commonly used methods to measure inner experience include event recording, questionnaires, thought-sampling using ratings, thinking-out-loud, and descriptive thought-sampling (thought-listing). The event recording procedure requires subjects to indicate whenever a pre-decided thought occurs. This method essentially measures the frequency of thoughts, and is hence also referred to as "thought-counting".

Questionnaires have been the most widely used strategy for measuring cognitions (Clark, 1988) with the majority of the studies of restrained eaters employing this method (e.g. Dykens \& Gerrard, 1985). The accuracy of questionnaires, however, has been a topic of concern. Being retrospective measures of cognitions, questionnaires are prone to selective memory biases, post-performance rationalisations, and social desirability biases (Clark, 1988). Researchers have argued that responses to questionnaires may be based 
on general beliefs about thoughts, rather than the nature of the actual thoughts themselves (e.g. Davison, Robins \& Johnson, 1983) thereby cueing responses to items that are similar but not identical to the thoughts experienced by the subject.

Event sampling and questionnaires provide only limited information regarding human thought. General themes are obtainable but how and when these thoughts are experienced is not assessed. The thinking-out-loud ("think-aloud") and descriptive thought-sampling methods have an advantage in that they endeavour to reveal the exact nature of human thinking as it occurs. The think-aloud method requires the subject to speak his or her thoughts as they occur, usually during a structured task. It is claimed that this technique yields valid and complete data (Ericsson \& Simon, 1980). Cooper \& Fairburn (1992) and Jansen et al. (1988) employed this technique in their studies of the cognitions of restrained eaters.

In the late 1970's, Hurburt $(1979,1980)$ and Klinger (1978) independently designed a method to randomly collect spontaneous cognitions in vivo. They used a small, random-interval tone generator to cue subjects to write their current thoughts, feelings and behaviour throughout an ordinary day. Zotter \& Crowther (1991) utilised this "thought-sampling" method in their study of restrained eaters' cognitions. This method has many advantages in that it is relatively unobtrusive, allows thoughts to occur naturally, and requires minimal use of memory because the request is for immediate recall. Despite their advantages, the effectiveness of descriptive thought-sampling and think-aloud procedures have some limitations.

Firstly, it is generally believed that the think-aloud process runs a significant risk of interfering with or changing the natural occurrence of thoughts (Wilson, 1994). Secondly, different trains of thought can co-occur at a specific instant (Clark, 1988). With many cognitions at one time it is likely that some will be forgotten or passed over during the think-aloud and thought-sampling tasks. A subject may report a trivial train of thought at the expense of another simultaneously-occurring, more research-relevant 
thought. Researchers could instruct subjects to pay more attention to the thoughts relevant to the topic of interest but this would create substantial bias while also interfering with the production of naturally occurring thoughts. However, Heimberg, Nyman \& O'Brien (1987) have found that the nature of the instructions given to subjects only affects the total number of thoughts reported rather than their nature. Finally, there is the problems of censorship and social desirability (Clark, 1988) which is inherent in all selfreport measures.

In sum, the investigation of human inner experience is a difficult task, one in which further development of the measurement procedures is required. To date, however, no one method is considered significantly superior to any of the others (Clark, 1988). See Clark (1988), and Goldberg \& Shaw (1989) for comprehensive reviews of the validity and reliability of these and other methods.

The present study employed a descriptive thought-sampling method in order to investigate cognitions as they occured in the natural environment. The only other research of this nature in the area of restraint, Zotter \& Crowther (1991), signalled subjects at regular 30 minute intervals. It is proposed that their subjects could have anticipated the signals and this may have interfered with the validity of the cognitions collected. In the present study subjects were cued to report their thoughts by a randomly-occurring paging signal to reduce the likelihood of bias due to anticipation of the signal.

\subsection{Analysing Thought Transcripts}

Think-aloud and thought-sampling techniques produce qualitative data. There are two main approaches to qualitative research in the social sciences (Glaser \& Strauss, 1969). One approach involves the quantification of coded data in order to verify existing theories. The other approach emphasises the development of theory in which data are perused for properties of theoretical categories. The present study involved a combination of these approaches : grounded analysis. 
Grounded analysis is the method used to generate a grounded theory (Glaser \& Strauss, 1969). This is a dynamic process in which data collection, analysis, and theory formation are tightly interwoven. Researchers follow a prescribed set of procedures to systematically build and develop a theory through inductive reasoning. This new approach to the study of psychological phenomena has already made some useful contributions to the understanding of psychotherapy (Rennie, Phillips \& Quartaro, 1988) and sexual offending (Ward, Louden, Hudson, \& Marshall, 1995).

In grounded analysis, once an original research question is formulated, the researcher initiates data collection. This method stands out from other research strategies in its early introduction of data analysis. Grounded data analysis involves the development and categorisation of meaning units, and the refining of these categories through inductive reasoning. This process begins as soon as the initial data are collected. Data are arranged into meaningful clusters and overlapping clusters are encouraged (open categorisation). As the categorisation process proceeds, old categories are refined, and new categories are developed until each meaning unit is able to be placed into one category which captures its natural meaning (saturation). This is in stark contrast to traditional methods of content analysis in which data are forced to fit into categories that have been predefined from existing theory. The advantage of the category formation in grounded analysis is that it is directly derived from the data and subsequently tested against new data. The preservation of the essence of the data in grounded analysis is ensured by the requirement that each refinement of the categorical system must fit the data. Grounded analysis is thus considered a more rigorous and accurate method for analysing qualitative data than traditional methods.

Ideally, in order to uncover the true nature of the data, grounded researchers are required to approach the task with no preconceptions. Obviously this is not practically possible but there are ways in which this state of mind can be approximated. Strauss \& Corbin (1990) recommend that researchers avoid reading pertinent literature until their grounded theories take form. Only then should the evolving grounded theory be reviewed in the light of the literature. In addition, the grounded theory method requires that researchers be aware of their biases and to record these as they arise during the research 
process. This is done under the assumption that explicit acknowledgement of biases helps to contain their influence (Rennie et al., 1988). Finally, the fact that grounded approach forces researchers to "stay close to their data" (Rennie et al., 1988) leaves little room for unsubstantiated theory generation.

In sum, grounded analysis allows access to important aspects of human experience that are difficult to research using traditional methods. The present study required the analysis of cognitions. While cognitions have been studied using traditional methods (Zotter \& Crowther, 1991; Cooper \& Fairburn, 1992; Jansen et al., 1988), it is proposed that grounded analysis offers a much more rigorous, accurate and powerful tool for discovery by allowing sufficient freedom to explore complex phenomena. In the words of Rennie et al (1988) :

"Having the [grounded] method in hand is like carrying a flashlight that can be beamed on any aspect of a cluttered attic" (p.145).

\subsection{Aims of the Present Study}

In line with the philosophy of grounded theory the present study aimed to explore the in vivo cognitions of restrained and unrestrained eaters on a normal day and a day in which their food intake was restricted, rather than to investigate specific hypotheses. Only subjects who scored at the extremes of Herman \& Mack's (1975) Restraint Scale were used to ensure that restrained and unrestrained subjects differed significantly in their relative levels of dietary restraint. Failure to ensure adequate differences between restraint groups may be a major contributing factor to the lack of results in previous studies (e.g. Jansen et al., 1988). In addition, the reporting of cognitions in the present study was initiated by a random signal rather than at regular 30 minute intervals (Zotter \& Crowther, 1991) to decrease the probability that anticipation of the signal would bias the thoughts reported. Cognitions were collected under fasting and nonfasting conditions in order to explore the effects of food-deprivation on the cognitions of both groups. This is the first study of its kind to investigate the effects of food deprivation on cognitions. Finally, the grounded method used to analyse the cognitive data was more rigorous than the traditional qualitative methods used by other restraint studies. 


\section{METHODS}

\subsection{Subjects}

Twenty women completed the study. Ten of these women were currently dieting (restrained eaters). The other ten women were not currently dieting and did not have a history of food restraint (unrestrained eaters). The women were recruited from advertisements placed on notice boards around the campus of the University of Canterbury, at local Christchurch gyms, and diet centres. The advertisements invited women who were currently dieting or who never dieted to participate in a study examining the relation between "nutrition and thoughts". In order to be eligible to take part in the study the women had to be between the ages of 18 and 40 years old, nonsmokers, medication free, and physically healthy. The advertisement also stated that women who completed the study would receive $\$ 30$ payment. Demographic data on the restrained and non-restrained samples are presented in Table 2. Two-tailed t-tests revealed that the two groups did not significantly differ with respect to their demographics.

\section{Table 2.}

Characteristics of the Restrained and Unrestrained Eaters

\begin{tabular}{|c|c|c|c|c|c|c|}
\hline \multirow[b]{2}{*}{ Variable } & \multicolumn{3}{|c|}{$\begin{array}{l}\text { Restrained eaters } \\
\quad(N=10)\end{array}$} & \multicolumn{3}{|c|}{$\begin{array}{l}\text { Unrestrained eaters } \\
\qquad(\mathrm{N}=10)\end{array}$} \\
\hline & Mean & SD & Range & Mean & SD & Range \\
\hline Age (yrs) & 24.6 & 8.4 & 21 & 24.6 & 5.5 & 15 \\
\hline Height (cm) & 164.7 & 4.3 & 15 & 168.1 & 6.4 & 20 \\
\hline Weight (kg) & 66.8 & 14.1 & 42 & 65.8 & 7.6 & 24 \\
\hline BMI & 25.3 & 5.1 & 17 & 23.3 & 2.6 & 9 \\
\hline Highest past adult weight $(\mathrm{kg})$ & 73.2 & 17.3 & 51 & 67.6 & 7.7 & 22 \\
\hline Lowest past adult weight $(\mathrm{kg})$ & 57.9 & 8.3 & 31 & 58.6 & 9.0 & 24 \\
\hline
\end{tabular}




\subsection{Instruments}

\section{Quantitative measures}

\section{Beck Depression Inventory $(B D I)$}

The revised BDI (Beck, Rush, Shaw, \& Emery, 1979) is a 21-item self-report inventory designed to assess the severity of behavioural and cognitive correlates of depression in adolescents and adults. Each item consists of a group of four statements of increasing severity. The subject is required to circle the statement or statements which best describe the way he or she has been feeling in the week prior to and including the day of administration. The higher the score, the more severe the depressive symptomatology. The BDI has been shown to be a valid and reliable measure of current depressive symptom severity (Beck \& Steer, 1987).

\section{Eating Disorders Inventory (EDI)}

The EDI (Garner \& Olmsted, 1984) is a 64-item self-report questionnaire designed to measure eight areas that are clinically relevant to eating disorders. Subjects are required to respond to each item by indicating the frequency with which the item relates to them on a six-point Likert scale ranging from "always" to "never". Three subscales measure attitudes and behaviours related to eating, appearance and weight (Drive for Thinness, Bulimia, Body Dissatisfaction), and the other five subscales assess a broader, more general range of constructs associated with eating disorders (Ineffectiveness, Perfection, Interpersonal Distrust, Interoceptive Awareness, Maturity Fears).

In brief, the Drive For Thinness subscale measures the subject's preoccupation with dieting and the excessive fear of weight gain, the Bulimia subscale assesses the subject's tendency to binge and the Body Dissatisfaction subscale assesses dissatisfaction with the shape and size of the hips, thighs, stomach and buttocks. The Ineffectiveness subscale measures the constructs of inadequacy, ineffectiveness and worthlessness, the Perfectionism subscale measures the tendency to believe that perfection is attainable, and the Interpersonal Distrust subscale measures the subject's reluctance to become closely 
involved with others. The Interoceptive Awareness, and Maturity Fears subscales assess the degree of awareness of internal states and the fear of adulthood, respectively. The EDI has been shown to be both a valid and reliable assessment device (Garner, 1991).

\section{Structured Clinical Interview for Diagnostic and Statistical Manual of Mental} Disorders 3rd edition - Revised (DSM-III-R) (SCID)

The SCID (American Psychiatric Association, 1990) is a structured interview employed to determine the presence of psychiatric disorders documented in the DSM-III-R (APA, 1990). Sections H.1 - H.4 are designed to establish whether a patient meets the DSM-III-R criteria for the diagnoses of Anorexia Nervosa or Bulimia Nervosa.

\section{The Short form of the Restraint Scale}

The Restraint Scale used in this study is a 5-item interview questionnaire compiled by Herman \& Mack (1975) (see Appendix). It was derived from a 10-item restraint scale originally selected on the basis of face validity which included questions relating to dietary concern and weight fluctuation. Of these 10 items, 5 were found to be internally consistent with an item-whole correlation of over 0.15 , and a coefficient (alpha) of 0.65 . In the present study restrained eaters were operationally defined as subjects who were currently dieting and who scored at or above 8 points on the Restraint Scale and unrestrained eaters were those who never dieted and scored 3 or less.

\section{Qualitative Measure : Grounded Analysis}

The present study employed the grounded theory approach to formulate categories true to the data. These categories were then analysed quantitatively.

Two steps were essentially involved in the categorisation of the data. First, the transcripts were divided into meaning units. In the present study meaning units were formed by breaking the transcripts into phrases which conveyed new information or additional concepts to the unit immediately before. An example of this step is provided below : 
"I'm really really hungry now. I have got a sore stomach and my skin is feeling awful and zitty. I have to lose weight before the lingerie modelling, I've got to get skinnier and more toned for that so this starvation thing is going to be good. I'm a bit cold but feel fine."

The above extract from a restrained eater's transcript was divided into the following units of analysis.

Unit $1:$ :I am really really hungry"

Unit 2 : "I have got a sore stomach"

Unit 3 : "My skin is feeling awful and zitty"

Unit 4 : "I have to lose weight"

Unit 5 : "This starvation is going to help me lose weight"

Unit 5 : "I'm a bit cold"

Unit 6 : "Feeling fine"

Step 2 began with open categorisation in which the units of analysis were sorted into overlapping clusters based on their meaning. These clusters were descriptively labelled to form categories. The constant comparative method of grounded analysis (Glaser \& Straus, 1967) was employed to refine the categories. This involved an ongoing process in which data collection and inductive categorisation of data were systematically repeated until the categories became saturated i.e. mutually exclusive. The categories in the present study were developed over a period of approximately 6 months.

\subsection{Procedure}

Women who replied to the advertisement were initially screened over the telephone to ensure they met the basic criteria of age 18- 40 years old, non-smoker, medicationfree, and physically healthy. The Restraint Scale was then administered over the phone and women who met the criteria for restrained or unrestrained eaters were invited to attend a screening interview in person.

During the interview the requirements of the study were described and informed consent was obtained. The women were then administered the SCID and BDI. Women 
who indicated they had a history of an eating disorder and/ or evidenced significant depressive symptomatology (scored above 10 on the $\mathrm{BDI}$ ) were excluded from the study. Women who were eligible to continue were asked to complete the EDI. Current height and weight measurements were obtained and Body Mass Indexes [BMI (kg/m2)] were calculated.

Prior to the study subjects were trained in food-intake recording, cognitive selfmonitoring, and equipment usage. The women were shown how to keep a detailed record of their food intake using "Instructions for Keeping a Diet Record" [Bulik, 1992, pp. 59-60, (see Appendix B)]. The researcher then modelled a correct entry on one of the provided recording forms using the subject's most recent meal as an example.

Training in cognitive self-monitoring included a brief description of what behaviour and feelings were and how they differed from cognitions. Behaviour was defined as observable actions like walking, eating, sleeping and reading. Feelings were described as emotions such as happy, sad, and angry. Cognitions were given more weighting in the training session as thoughts were the phenomena of primary interest to the study. The following points about cognition were highlighted :

a) Thought can be visual or verbal. Visual thoughts include images and memories. Verbal thoughts are words and sentences.

b) Many thoughts can occur at one time. These thoughts are not necessarily logically related - you can be thinking about two separate topics at once.

c) Thoughts feed off each other and can jump from topic to topic.

Examples of each point were provided and subjects were given a handout to take with them (see Appendix C).

Subjects were shown how to operate the pager and tape-recorder and practised this during the session. The researcher then modelled a recording illustrating the format of 
information and the type of content required. The following instructions regarding the recording of their cognitions were provided :

"When you are paged you are to go to a private place and record

a) the time,

b) the situation or behaviour you are involved in,

c) your thoughts in the few minutes immediately prior to the "beep", and

d) any prominent feelings.

Do not miss an entry. If you are unable to speak into the tape recorder immediately, write down your thoughts on a piece of paper and record these into the tape recorder as soon as possible afterwards".

A practice session was arranged in which the subject was paged for five consecutive hourly intervals. The subject was instructed to record both her food intake and cognitions during this period. The data were subsequently reviewed by the researcher to ensure the information being collected was in the appropriate form. Following this, dates were arranged for a fasting day and a non-fasting day, one week apart. Fasting was defined as not eating, and only drinking sugar-free beverages. The order of the fasting and nonfasting days was randomly assigned.

For the fasting condition subjects were required to fast for 24 hours, from $6 \mathrm{pm}$ one evening (day 1) until 6pm the next (day 2). Subjects were instructed to record their fluidintake during this period. On completion of the fasting period, subjects were asked to eat a provided meal which consisted of a TV dinner, 1 Cookie Time biscuit, and 1 apple. The women were given a choice of three TV dinner meals which included Watties Lasagne, Healthy Choice Chicken in Light Mustard Sauce, and Fetticine Chicken. Following the meal, the subjects were permitted to eat what they wished and were required to record all food-intake until 10pm on day 2 . Thought-recording began at $8.30 \mathrm{am}$ and ended at $10 \mathrm{pm}$ on day 2 to enable thoughts during and after the fasting period to be obtained. Subjects were paged randomly at approximately 40 minute intervals. This was achieved using a Telecom paging system which enabled the researcher to programme the times in advance. Twenty six paging signals were sent in 
total. In addition to recording their thoughts immediately prior to each signal the subjects were instructed to record their thoughts immediately prior to, during, and after eating the meal provided. They were also requested to record their thoughts before retiring to bed on day 2.

The fasting and non-fasting days were designed to be as similar as possible except for the fasting state. Aside from the procedures required for the study, subjects were instructed to carry out their days as they normally would. The non-fasting condition involved the subjects eating as normally and recording their food and fluid intake from $6 \mathrm{pm}$ on day 1 until $10 \mathrm{pm}$ on day 2 . At $6 \mathrm{pm}$ on day 2 they were instructed to eat the provided meal (same as that provided in the fasting condition). Thought-recording spanned the same time period and included the same number of paging signals as in the fasting condition. Additional thoughts surrounding the meal provided and before retiring to bed were also requested. The instruction sheets received by the subjects for both conditions are shown in Appendix D. 


\section{RESULTS}

\subsection{Self-report questionnaires}

\section{Restraint}

A two-tailed t-test of the restraint scores obtained on Herman \& Mack's (1975) Restraint Scale revealed that the restrained eaters (RE) had significantly higher levels of restraint compared to the unrestrained eaters (URE) $\{[\mathrm{t}(18)=17.64, \mathrm{p}<. .01 ; \mathrm{RE}=$ 9.3, URE $=2.1]\}$.

\section{Eating Disorders Inventory (EDI)}

The mean scores of the restrained and unrestrained eating groups on the eight dimensions of the EDI are shown in Table 3. Two-tailed t-tests revealed that the restrained eaters exhibited significantly higher scores than the unrestrained eaters on the following dimensions : Drive for Thinness, Bulimia, Body Dissatisfaction, Perfectionism, and Interoceptive Awareness. The restrained eaters' EDI scores on these subscales were comparable to the scores of eating disordered patients and their scores on the other subscales were slightly above nonpatient norms (Garner, 1991, p.14). All of the unrestrained group mean scores were typically below nonpatient group norms. (Garner, 1991, p.14).

\section{Beck Depression Inventory (BDI)}

The restrained eaters scored significantly higher than the unrestrained eaters on the $\mathrm{BDI}[\mathrm{t}(18)=4.5, \mathrm{p}>.01 ; \mathrm{RE}=8.4, \mathrm{URE}=2.9]$, however all scores were within the "none to minimal depression" range $(0-10)$. 
Table 3:

Means and Standard Deviations of Scores on the Eight Dimensions of the EDI for Restrained and Unrestrained Eaters

$\begin{array}{ll}\text { Restrained eaters } & \text { Unrestrained eaters } \\ (\mathrm{N}=10) & (\mathrm{N}=10)\end{array}$

Dimension mean SD mean SD t-score $\mathrm{p}<$

Drive for Thinness

Bulimia

Body Dissatisfaction

Ineffectiveness

Perfectionism

Interpersonal Distrust

Interoceptive Awareness

Maturity Fears

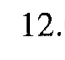

2.3

$20.9 \quad 7.3$

$5.6 \quad 5.9$

$8.3 \quad 5.8$

1.8

3.

4.1

4.4

1.5

2.3

6.68

.01

0.1

0.3

$3.63 \quad .01$

7.7

8.3

$3.77 \quad .01$

2.4

2.6

1.56 n.s

$\begin{array}{ll}5.8 & 3.5\end{array}$

2.7

$2.36 \quad .05$

$\begin{array}{lll}1.8 & 2.3 & 1.8\end{array}$

2.0

$0.00 \quad$ n.s

$\begin{array}{lll}3.1 & 2.7 & 0.8\end{array}$

1.0

$2.53 \quad .05$

$3.8 \quad 3.8$

2.2

$2.08 \quad$ n.s

\subsection{Analyses of the Thought Transcripts}

\section{Step One : Grounded Analysis : Category formation}

The original transcripts were broken down into 5480 codeable units by the researcher. An interrater reliability check of this process was carried out by an independent analyst. Interrater agreement was calculated from the ratings of a randomlyselected twenty percent sample of the total transcripts. The average percentage of agreement between the two raters was $88 \%$.

All of the units were then coded into basic meaning categories using the principles outlined by grounded analysis. Three mutually exclusive major categories evolved from the data. These included thoughts relating to A) food and eating, B) self, and C) others. These categories were hierarchically arranged such that any thoughts pertaining to food 
were always coded as food thoughts regardless of whether the other categories, self or others, were indicated. Thoughts unable to be coded in either of the three categories were coded in a fourth category X) miscellaneous. Within each category several sub-categories were formed (see Table 4). Some of these categories were dimensionalized on a 5-point Likert scale.

An interrater reliability check of this process was carried out by an independent rater. Rating categories were operationally defined and examples were provided for each category. A randomly chosen twenty percent sample of the total transcripts were selected for interrater agreement comparisons. The average percentage of agreement between the researcher and the independent rater was a satisfactory $83 \%$.

The categories were as follows :

\section{A Food/ Eating}

The Food/eating category (total number of thoughts in category : $\mathrm{N}=1119$ ) contained six subcategories :

The first food category, Hunger state $(\mathrm{N}=202)$, included statements expressing a degree of hunger. Statements were rated along a 5-point Likert scale ranging from extreme hunger to extreme satiety. The statement "I am starving" was rated as extreme hunger, whereas the statement "I feel so bloated" was rated as extreme satiety.

A second food category, Desire for food $(\mathrm{N}=45)$, contained statements expressing a desire to eat or a desire for food irrespective of hunger state. The degree of desire for food could be rated on a 5-point Likert scale from minimal to substantial levels of desire. An example of minimal desire for food was "I don't want to eat those mushrooms". An example of substantial desire was "I would really really love some chocolate". 
Table 4

Categories obtained through Grounded Analyses of the Thought Transcripts of Restrained and Unrestrained Eaters.

\section{CATEGORIES}

A) FOOD/EATING

1. Hunger state

[extreme hunger (1) - satiety (5)]

2. Desire for food

[minimal (1) - substantiai (5)]

3. Food Evaluation

[negative (1) - positive (5)]

4. Eating patterns and Attitudes towards Food

5. Food/Eating Planning

6. Food-Miscellaneous

B) SELF

1. Physical state

[negative (1)-positive (5)]

2. Self-Planning

3. Self-Observation

4. Self-Evaluation (judgment)

a) Personality/ behaviour

b) Appearance/ weight

[negative (1) - positive (5)]

[negative (1) - positive (5)]

5. Emotional state

[negative (1) - positive (5)]

6. Self-Miscellaneous

C) OTHERS

1. Observation of others

2. Evaluation of others (judgement)

a) Personality/ behaviour [negative (1)-positive (5)]

b) Appearance/ weight [negative (1) - positive (5)]

3. Evaluation of self by others

a) Personality/ behaviour [negative (1) - positive (5)]

b) Appearance/ weight [negative (1)-positive (5)]

4. Others-Miscellaneous

X) MISCELLANEOUS 
Evaluative statements about food were coded in the category Food evaluation. $(\mathrm{N}=$ 200) and rated on a 5-point-Likert scale ranging from an extremely critical or negative statement about food to an extremely positive or complimentary statement about food. Examples of each extreme include "The meal looks disgusting", and "Dinner smells delicious", respectively.

An Eating Patterns and Attitudes toward Food category ( $\mathrm{N}=274)$ contained statements describing the subject's typical eating patterns, general attitudes towards food and eating and observations about their eating behaviour. Statements that were coded in this category included "I always eat lunch", "Not eating will be good for my diet" and "I ate everything in sight".

Statements regarding plans to eat or to prepare food were coded within the Food/eating - planning category $(\mathrm{N}=281)$. Examples of such statements include "I should start cooking the lunch", "I think I will save the cookie time for later", and "I will go and get a sandwich".

A Food-miscellaneous category $(\mathrm{N}=113)$ was also included within the food category to contain statements relating to food and eating that were unable to be coded in the other food categories. Statements about others and food, for example "Ross is having salmon on toast for lunch" and "Julia has gone to do the grocery shopping" were included in this category.

\section{B. Self}

The Self category $(\mathrm{N}=2472)$ contained seven subcategories :

Physical state $(\mathrm{N}=287)$, pertained to statements regarding the current state of physical well-being of the subject. This included thoughts about energy, fitness and health-related issues. States of hunger were not coded in this category but were coded under a food category. Physical state could be rated from extremely negative to extremely positive states of physical well-being. The statement "I' $m$ absolutely exhausted" was 
coded as an extreme negative state of physical well-being whereas "it makes me feel so energetic" was coded as an extremely positive statement about the individual's current physical state.

The second subcategory within the Self category included statements that specified possible future courses of action, excluding plans related to eating or food. This category was termed Self-Planning $(\mathrm{N}=747)$. Examples of thoughts that were coded in this category include "I must do my Christmas shopping this afternoon" and "I will go and get some wood for the fire".

Neutral observations of the self, excluding observations about eating patterns or food preferences, formed the basis of the third Self category, Self-Observation. $(\mathrm{N}=$ 331). Such statements were descriptive of the subject's behaviours, thoughts, and attitudes. Statements that were rated in this category were "I always seem to wear black to weddings" and "I prefer to walk to Varsity."

Statements which were evaluative or judgmental about the self were coded under Self-Evaluation. This category was divided into two sub-categories : Personality/ behaviour $(\mathrm{N}=43)$ and Appearance / weight $(\mathrm{N}=120)$. Both sub-categories were dimensionalized on a 5-point Likert scale from extremely negative or critical evaluations to extremely positive or complementary evaluations. The Personality/behaviour subcategory contained evaluative statements about the subject's personality and behaviour. "I am a nasty, worthless person" was coded as an extremely negative evaluation of the subject's personality whereas "I am a great dancer" was coded as a highly complimentary or positive statement about the subject's behaviour. The Appearance/weight subcategory included evaluative statements about the subject's appearance and weight. An example of an extremely negative evaluation of the subjects appearance was "Yuck! My legs are so fat". "I am looking really good tonight" was rated as an extremely complimentary statement about the individual's appearance. 
Thoughts expressing or indicating that the subject was experiencing an affective state were coded in the subcategory of Self, Emotional state $(\mathrm{N}=753)$. Each statement was further rated on a 5-point Likert scale ranging from extremely negative to extremely positive affective states. An affective statement that was rated as extremely negative was "I am so frustrated" whereas "Feeling really happy" was rated as an extremely positive emotional state.

The final self subcategory was labelled miscellaneous $(\mathrm{N}=191)$. Statements included in this category were thoughts pertaining to the self that could not be placed in any of the other Self sub-categories. Such statements included the subject's hopes, memories, and philosophical thoughts about life, for example "When I was little I always thought that I'd want to get really really old" and "The quiet times with your best friend are the best times".

\section{Others}

The Others category $(\mathrm{N}=948)$ contained six subcategories :

Neutral statements that described the behaviour, affect or attitudes of another individual or a group of others were coded in the Others subcategory of Observation of others $(\mathrm{N}=278)$. Examples of statements coded as observation of others were "Jo has offered to pay for it for me" and "That lady is sitting there all hunched up".

The Evaluation of others category contained two sub-categories : judgmental statements about others personality or behaviour [Personality/behaviour $(\mathrm{N}=253)]$ and evaluative statements about another's appearance or weight [Appearance/weight $(\mathrm{N}=$ 55)]. All evaluative statements about others were rated on a 5-point Likert scale ranging from extremely negative judgements to extremely positive or complementary judgements. An example of an extremely negative evaluation of another's behaviour was "She is so patronising" while an example of an extremely positive evaluation about another's 
personality was "She's a lovely person". Extremely negative evaluations of another's appearance included statements such as "She is so fat", and "She looks like a gorilla". Extremely positive evaluations included "He is very good looking" and "She has a great toned upper-body".

The Others category contained another evaluation subcategory, Evaluation of self by others. This category included statements that presumed an evaluation of the self by others. This category contained the two dimensionalised sub-categories : Personality/ behaviour $(\mathrm{N}=32)$ and Appearance/ weight $(\mathrm{N}=6)$. These sub-categories are defined as above but pertain to expectations of evaluation from others. An example of a statement expecting an extremely negative evaluation from another about the subject's personality or behaviour was "She probably thinks I have no brains at all". A evaluation of the subject's personality or behaviour was "They might think that I am really intelligent". In order to be rated as an expectation of an extremely negative evaluation by others, the statement would be along the lines of "He will think my legs are disgusting" whereas an expectation of an extremely positive judgement by others would be "I will get heaps of looks tonight".

Finally, the Others category contains a miscellaneous category termed Others -Miscellaneous $(\mathrm{N}=324)$ which includes statements pertaining to others that cannot be placed into any of the above categories regarding others. Examples of statements that would be coded in this category include "My parents are going away", "Thinking about my grandmother", and "I wonder when Jo is coming around".

\section{Miscellaneous}

The Miscellaneous category $(\mathrm{N}=947)$ contained statements that were primarily about topics other than food and eating, self, and others. This category included statements about the weather and environment, finances, and work and study tasks as well as various other statements unable to be coded in the three major categories. 
Statements coded in this category were "It's so cold outside", "This house is too messy", "I can't afford a $\$ 300$ phone bill" "Record the stock market earnings " and "Shortland Street is on television".

\section{Step 2 : Quantitative analyses}

\section{A) Percentage of thoughts comparisons}

\section{Total raw number of thoughts}

In total, 5480 thoughts were recorded. A $2 \times 2$ chi squared test of the raw number of total thoughts between groups across conditions revealed a significant main effect for group $\left[\chi^{2}(1)=84.9, p<.01\right]$. Overall, the restrained group produced significantly more thoughts in total $(x=154.1, \mathrm{SD}=59.6)$ and the unrestrained group produced significantly less thoughts $(x=119.8, \mathrm{SD}=76.9)$ than would have been expected by chance. A significant main effect for condition was also obtained $[\chi 2(1)=$ $15.8, \mathrm{p}<.01]$ with significantly more thoughts produced on the fasting day $(\mathrm{M}=$ 144.4, $\mathrm{SD}=70.2)$ and significantly fewer thoughts on the non-fasting day $(\mathrm{M}=$ $136.9, \mathrm{SD}=70.1)$ than would have been expected by chance.

In addition a significant interaction effect was evident $[\chi 2(1)=20.9, p<.01]$. The restrained group produced significantly more thoughts on the fasting day $(\mathrm{M}=$ $170.7, \mathrm{SD}=63.8)$ but produced significantly fewer thoughts on the non-fasting day $(\mathrm{M}=137.4, \mathrm{SD}=53.0)$ than would have been expected by chance whereas the total number of thoughts for the unrestrained group on the fasting day $(\mathrm{M}=118, \mathrm{SD}=$ 69.2) and the non-fasting day $(M=121.9, S D=87.7)$ did not differ significantly. 


\section{Major category percentages}

The significant differences in the raw number of thoughts produced by the restrained and unrestrained eaters under both conditions required that the percentages of thoughts in each of the major categories be calculated for each subject. Analyses of the distribution of these scores indicated non-parametric statistical tests were required. Mean percentage scores for each group were obtained and chi-squared analyses were then performed in order to determine whether restrained and unrestrained eaters differed in the percentage of thoughts in each of the categories extracted in Phase 1.

A contingency table revealed no significant interaction effects for major category vs. group $[\chi 2(1)=0.2, n s]$ or for major category vs. condition $[\chi 2(1)=1.1, \mathrm{p}<\mathrm{ns}]$ but a main effect for major category was evident overall. Both restrained and unrestrained eaters had a significantly higher percentage of thoughts related to self and a significantly lower percentage of thoughts related to others, and miscellaneous issues than would be expected by chance under the fasting and nonfasting conditions $\left[\chi^{2}(1)=25.2, \mathrm{p}<.01\right]$. This is illustrated in Figure 1. Table 5. provides the mean percentage of thoughts for both groups under each condition.

\section{A: Restrained Eaters}

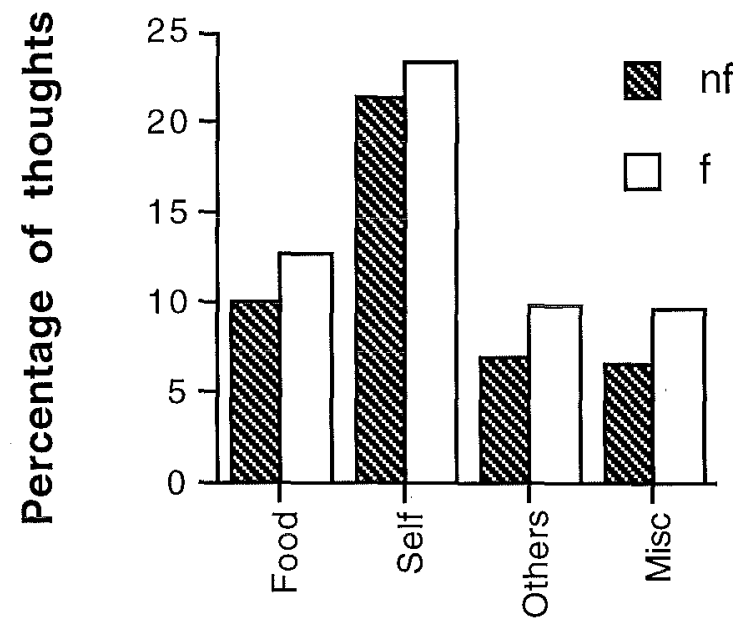

Category

\section{B: Unrestrained Eaters}

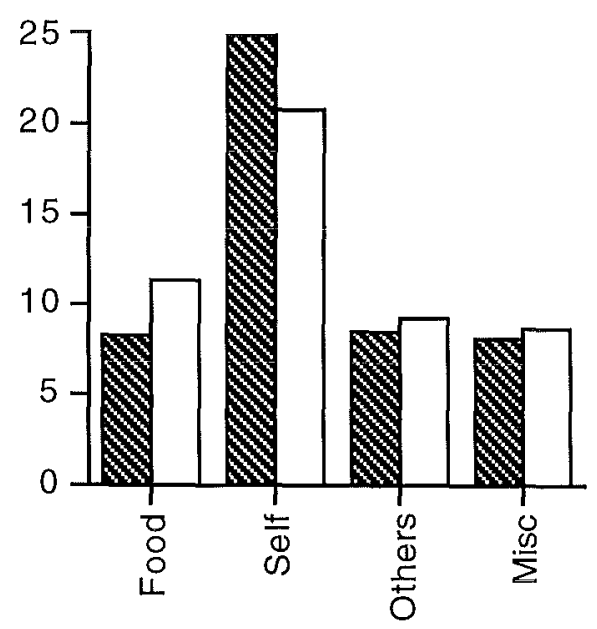

Category

Figure 1.

Percentage of thoughts in each of the four major categories (Food, Self, Others and Miscellaneous) for Restrained Eaters (Panel A) and Unrestrained Eaters (Panel B) in both Fasting (f) and Nonfasting (nf) conditions. 
Table 5.

Percentage of Thoughts in each Major Category as a Mean of the Percentage of each Subject's Total number of Thoughts in each Group across Both Conditions.

\begin{tabular}{|c|c|c|c|c|c|c|c|c|}
\hline \multirow[b]{3}{*}{ Major category } & \multicolumn{4}{|c|}{ Restrained eaters } & \multicolumn{4}{|c|}{ Unrestrained eaters } \\
\hline & \multicolumn{2}{|c|}{$\mathrm{nf}$} & \multicolumn{2}{|c|}{$\mathrm{f}$} & \multicolumn{2}{|c|}{$\mathrm{nf}$} & \multicolumn{2}{|c|}{$\mathrm{f}$} \\
\hline & M & SD & M & $\mathrm{SD}$ & $\mathrm{M}$ & SD & $\mathrm{M}$ & SD \\
\hline Food & 10.0 & 3.5 & 12.8 & 4.6 & 8.2 & 3.2 & 11.4 & 4.4 \\
\hline Self & 21.4 & 6.3 & 23.4 & 5.8 & 24.9 & 5.6 & 20.8 & 4.4 \\
\hline Others & 7.0 & 3.5 & 9.9 & 4.1 & 8.4 & 2.3 & 9.1 & 3.7 \\
\hline Miscellaneous & 6.6 & 1.8 & 9.7 & 3.2 & 8.0 & 3.8 & 8.7 & 2.8 \\
\hline
\end{tabular}

\section{Subcategories}

Analyses of the subcategories within the major categories of food, self, and others were carried out in order to uncover differences in the percentage of thoughts in each subcategory. The mean percentages of thoughts in each subcategory for each group under each condition are displayed in Table 6.

\section{Food}

Analysis of the subcategories of the major category "Food" revealed a significant main effect for condition for the relative percentage of total food thoughts across conditions $(\chi 2(1)=166.4, p<.01)$. For both groups, there was a significantly higher proportion of thoughts about food under the fasting condition $(\mathrm{MRE}=57.2, \mathrm{SD}=10.7$; $\mathrm{MURE}=57.7, \mathrm{SD}=11.7)$ compared to the non-fasting condition $(\mathrm{MRE}=42.8, \mathrm{SD}=$ 10.7; $\mathrm{MURE}=42.3, \mathrm{SD}=11.7)($ See Figure 2$)$. No significant interaction effects were yielded for this comparison. 
Table 6.

Means and Standard Deviations of the Frequency of Thoughts in each Subcategory as a Percentage of each Major Category.

\section{Percentage of Major Category}

\begin{tabular}{|c|c|c|c|c|}
\hline \multirow{2}{*}{$\begin{array}{c}\text { Major category } \\
\text { Subcategory }\end{array}$} & \multicolumn{2}{|c|}{ Restrained eaters } & \multicolumn{2}{|c|}{ Unrestrained eaters } \\
\hline & NF & $\mathrm{F}$ & NF & F \\
\hline & $\mathrm{M} \quad(\mathrm{SD})$ & $\mathrm{M}$ & $\mathrm{M} \quad(\mathrm{SD})$ & $\mathrm{M}$ \\
\hline
\end{tabular}

\section{Food}

Hunger state

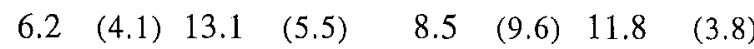

Desire for food

Evaluation of food

$\begin{array}{llllllll}2.4 & (2.1) & 2.1 & (2.0) & 0.7 & (1.2) & 3.9 & (4.0)\end{array}$

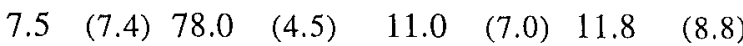

Eating patterns and

attitudes toward food

$\begin{array}{llllllll}11.7 & (7.1) & 14.7 & (8.6) & 5.1 & (4.3) & 12.6 & (7.0)\end{array}$

Food/eating planning

Food-miscellaneous

Total thoughts about food

$\begin{array}{llllllll}11.9 & (7.9) & 14.7 & (5.6) & 12.1 & (6.7) & 14.3 & (5.6)\end{array}$

$\begin{array}{llllllll}3.1 & (4.0) & 4.7 & (6.3) & 4.8 & (4.2) & 3.4 & (3.9)\end{array}$

$42.9(10.7) 57.2(10.7) \quad 42.3(11.7) 57.7 \quad(11.7)$

\section{Self}

Physical state

$\begin{array}{llllllll}4.2 & (4.1) & 7.6 & (5.6) & 4.5 & (3.7) & 5.8 & (4.9)\end{array}$

Self-planning

Self-observation

$\begin{array}{llllllll}12.7 & (4.8) & 14.7 & (8.6) & 19.9 & (9.5) & 12.8 & (8.2)\end{array}$

$\begin{array}{lllllllll}6.7 & (4.2) & 7.5 & (3.7) & 8.0 & (4.9) & 4.4 & (2.8)\end{array}$

Self-evaluation

Personality \& Behaviour

$\begin{array}{llllllll}1.1 & (1.5) & 0.6 & (0.8) & 1.0 & (1.2) & 0.3 & (0.5)\end{array}$

Body \& Appearance

Emotional state

Self-miscellaneous

Total thoughts about self

$\begin{array}{llllllll}3.9 & (6.3) & 3.3 & (4.7) & 1.2 & (1.3) & 2.5 & (2.6)\end{array}$

$\begin{array}{llllllll}14.2 & (6.2) & 17.1 & (8.3) & 15.4 & (5.8) & 17.1 & (5.9)\end{array}$

$\begin{array}{llllllll}4.2 & (4.3) & 2.8 & (1.9) & 4.2 & (1.9) & 2.9 & (3.3)\end{array}$

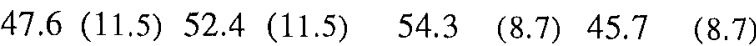

\section{Others}

Observation of others

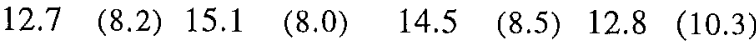

Evaluation of others

\section{Personality \& Behaviour Body \& Appearance}

Evaluation of self by others

Personality \& Behaviour

Body \& Appearance

Others-miscellaneous

Total thoughts about others $\begin{array}{llllllll}9.1 & (5.5) & 15.2 & (8.4) & 14.4 & (9.1) & 13.8 & (10.9)\end{array}$

$\begin{array}{llllllll}3.3 & (4.9) & 3.2 & (2.0) & 1.2 & (2.0) & 2.7 & (4.8)\end{array}$

$\begin{array}{llllllll}1.2 & (2.4) & 2.4 & (3.1) & 0.7 & (1.5) & 12.8 & (3.7)\end{array}$

$\begin{array}{llllllll}0.0 & (0.0) & 0.5 & (1.1) & 0.2 & (0.6) & 0.4 & (0.9)\end{array}$

$12.9 \quad(7.3) \quad 24.4 \quad(15.4) \quad 18.3(12.6) \quad 18.5 \quad(10.7)$

$39.2(10.5) \quad 60.8(10.5) \quad 49.3(11.9) \quad 50.7 \quad(11.9)$ 


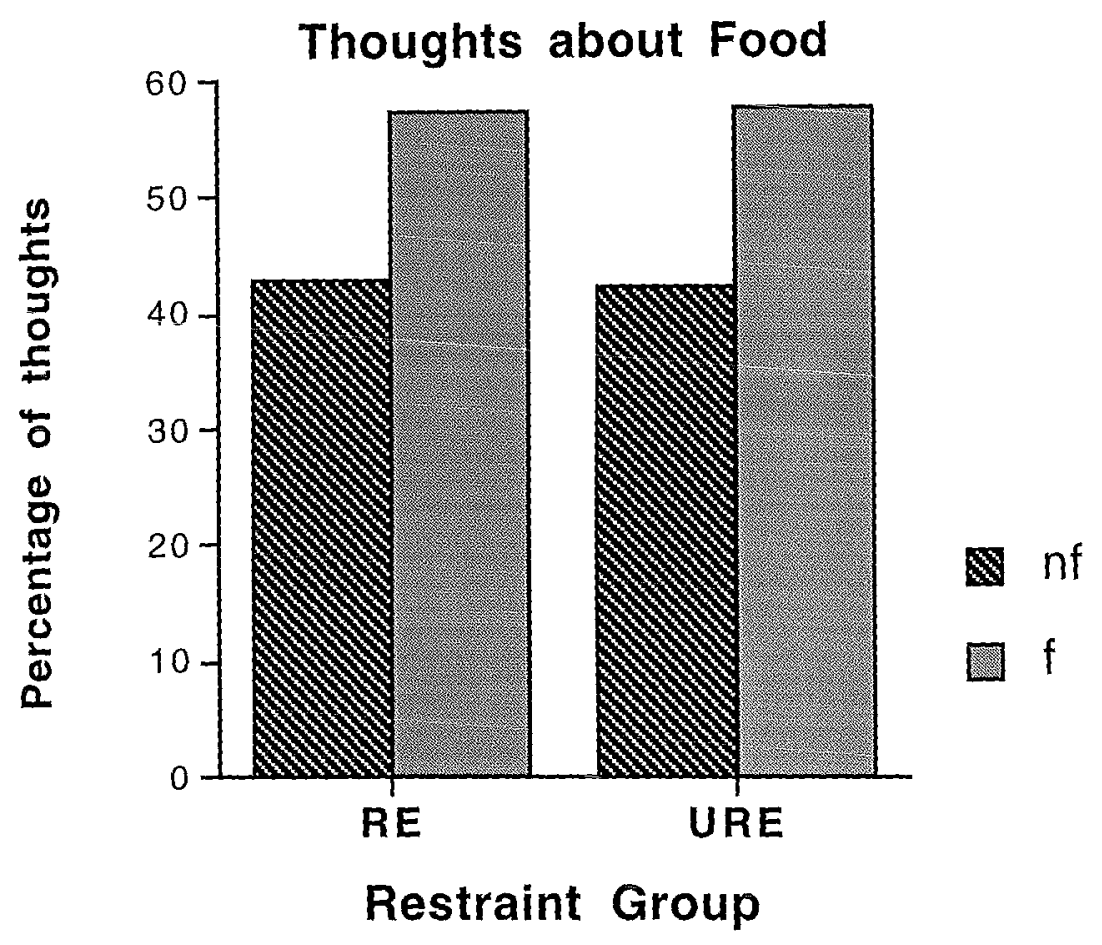

\section{Figure 2.}

Percentage of Thoughts about Food for Restrained (RE) and Unrestrained Eaters (URE) under Fasting (f) and Nonfasting (nf) conditions.

A contingency table of the proportion of thoughts in each subcategory revealed no significant interaction effects for subcategory vs. group $[\chi 2(1)=3.1$, ns $]$ or for subcategory vs. condition $[\chi 2(1)=2.1, \mathrm{~ns}]$, however a main effect for subcategory was found $[\chi 2(1)=43.8, \mathrm{p}<.01]$. Across both conditions and groups there was a significantly higher percentage of thoughts in the subcategories "Food-planning", "Attitudes toward food and eating", "Hunger state", and "Evaluation of food" and significantly fewer thoughts in the "Desire for food" and "Food-miscellaneous" subcategories than would have been expected by chance alone. 


\section{Self}

A contingency table of the sub-categories within the Self category revealed no significant interaction effects for subcategory vs. group $[\chi 2(1)=2.0$, ns $]$ or subcategory vs. condition $[\chi 2(1)=3.2$, ns $]$, however an overall main effect for subcategory was present. There was a significantly higher percentage of thoughts in the subcategories "self-planning" and "emotional state" and a significantly lower percentage of thoughts in "Self-evaluation of personality and behaviour", "Self-evaluation of body and appearance", and "Self-miscellaneous" than would be expected by chance $\left[\chi^{2}(1)=\right.$ $117.0, \mathrm{p}<.01]$. Restrained eaters and unrestrained eaters did not differ significantly from each other in their relative percentages of each subcategory under the non-fasting $[\chi 2$ (1) $=2.9, \mathrm{~ns}]$ or the fasting condition $\left[\chi^{2}(1)=1.1, \mathrm{~ns}\right]$.

\section{Others}

Contingency tables of the relative percentage of the thoughts in each subcategory in the major category of Others across condition and across groups yielded no significant interaction effects $\left[\chi^{2}(1)=1.7, \mathrm{~ns}\right]$ and $\left[\chi^{2}(1)=1.0, \mathrm{~ns}\right]$ respectively. A simple main effect for the restrained eaters was yielded when comparisons were made of the total number of thoughts about others across conditions. Restrained eaters had significantly more thoughts about others under the fasting condition $(\mathrm{M}=60.8, \mathrm{SD}=10.5)$ and significantly fewer thoughts about others under the non-fasting condition $(M=39.2, \mathrm{SD}$ $=10.5)$ than was expected by chance $\{[\chi 2(1)=4.7, \mathrm{p}<.05]$ [See Figure 3] $\}$.

Evidence of an overall main effect of subcategory was found with three of the subcategories, "Others-miscellaneous", “Observation of others” , "Evaluation of others' personality and behaviour", having a percentage of thoughts significantly higher and the remaining three subcategories, "Evaluation of others' body and appearance", "Evaluation of self's personality and behaviour by others", and "Evaluation of self's body and appearance by others", having a percentage of thoughts significantly lower than would have been expected by chance $\left[\chi^{2}(1)=143.0, p<.01\right]$. No other significant results were obtained in the analyses of Other subcategories. 


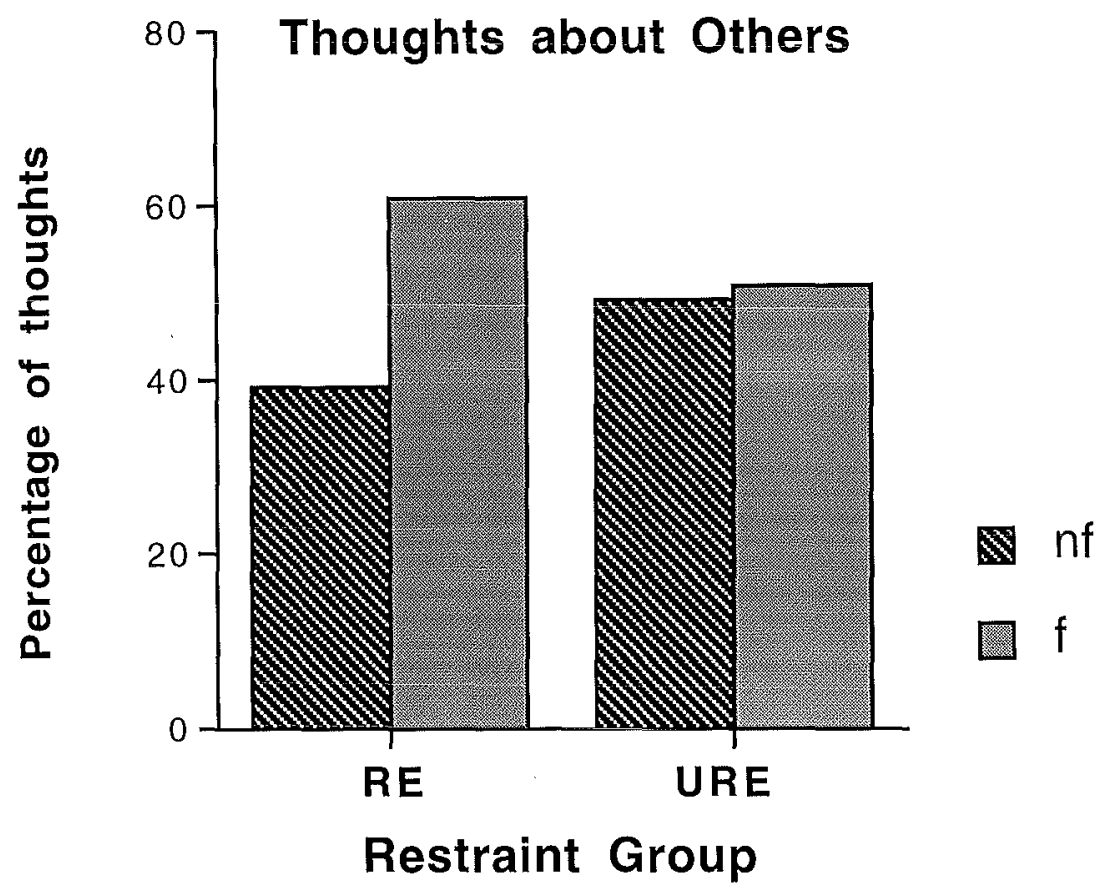

Figure 3.

Percentage of Thoughts about Others for Restrained (RE) and Unrestrained Eaters (URE) under Fasting ( $f$ ) and Nonfasting (nf) conditions.

\section{B) Nature of Thoughts Comparisons}

In order to analyse the dimensionalised subcategories each subject's average scores across the 5-point Likert scales were calculated (See Table 7) and comparisons between groups and across conditions were made using a series of $2 \times 2$ (group by condition) analyses of variance (ANOVA). Subjects who had not reported any thoughts regarding a particular subcategory were excluded from the analysis of that subcategory. 


\section{Table 7.}

Mean scores and Standard Deviations on the Dimensionalised Subcategories for Restrained and Unrestrained Eaters under Nonfasting (nf) and Fasting (f) conditions

\begin{tabular}{|c|c|c|c|c|c|c|c|c|}
\hline \multirow{3}{*}{$\begin{array}{l}\text { Major category } \\
\text { Dimensionalised Subcategory }\end{array}$} & \multicolumn{4}{|c|}{$\begin{array}{l}\text { Mean score on Di } \\
\text { Restrained eaters }\end{array}$} & \multicolumn{4}{|c|}{$\begin{array}{l}\text { mensionalised Scale } \\
\text { Unrestrained eaters }\end{array}$} \\
\hline & \multicolumn{2}{|c|}{$\mathrm{nf}$} & \multicolumn{2}{|r|}{$\mathrm{f}$} & \multicolumn{2}{|c|}{$\mathrm{nf}$} & \multicolumn{2}{|c|}{ f } \\
\hline & M & (SD) & M & (SD) & $\mathrm{M}$ & (SD) & M & $(\mathrm{SD})$ \\
\hline \multicolumn{9}{|l|}{ Food } \\
\hline Hunger state & 3.1 & $(0.8)$ & 3.8 & $(0.9)$ & 2.9 & $(1.6)$ & 4.1 & $(0.2)$ \\
\hline Desire for food & 2.5 & $(0.9)$ & 2.3 & $(0.9)$ & 2.8 & $(0.9)$ & 2.4 & $(0.7)$ \\
\hline Evaluation of food & 3.7 & $(0.6)$ & 3.4 & $(0.8)$ & 2.7 & $(0.5)$ & 3.2 & $(0.7)$ \\
\hline \multicolumn{9}{|l|}{ Self } \\
\hline Physical State & 1.8 & $(0.5)$ & 2.1 & $(0.4)$ & 2.0 & $(0.5)$ & 2.1 & $(0.3)$ \\
\hline \multicolumn{9}{|l|}{ Self-Evaluation } \\
\hline Personality \& behaviour & 2.2 & $(0.3)$ & 2.5 & $(0.7)$ & 3.3 & $(1.0)$ & 2.0 & $(0.0)$ \\
\hline Body \& appearance & 2.3 & $(0.4)$ & 2.7 & $(0.5)$ & 2.8 & $(0.3)$ & 2.7 & $(0.9)$ \\
\hline Emotional State & 2.7 & $(0.4)$ & 2.6 & $(0.2)$ & 2.6 & $(0.5)$ & 2.7 & $(0.3)$ \\
\hline
\end{tabular}

\section{Others}

Evaluation of others

Personality \& behaviour

$\begin{array}{llllllll}2.3 & (0.7) & 2.6 & (0.5) & 2.6 & (0.9) & 2.8 & (0.7)\end{array}$

Body \& appearance

$\begin{array}{llllllll}3.3 & (0.8) & 2.9 & (1.1) & 3.8 & (0.7) & 3.3 & (0.4)\end{array}$

Evaluation of self by others

Personality \& behaviour

$\begin{array}{llllllll}3.1 & (0.9) & 2.9 & (0.8) & 2.3 & (0.4) & 3.1 & (0.7)\end{array}$

Body \& appearance 


\section{Food}

Analyses of the dimensionalised food subcategories yielded only one significant result. A significant main effect for group in the "Evaluation of food" subcategory was found $[F(1,33)=6.6, p<.05]$. Overall, restrained eaters reported significantly higher evaluations of food $(M=3.6, S D=0.8)$ than the unrestrained eaters $\{[x=3.0, S D=$ 0.8] [See Figure 4]\}.

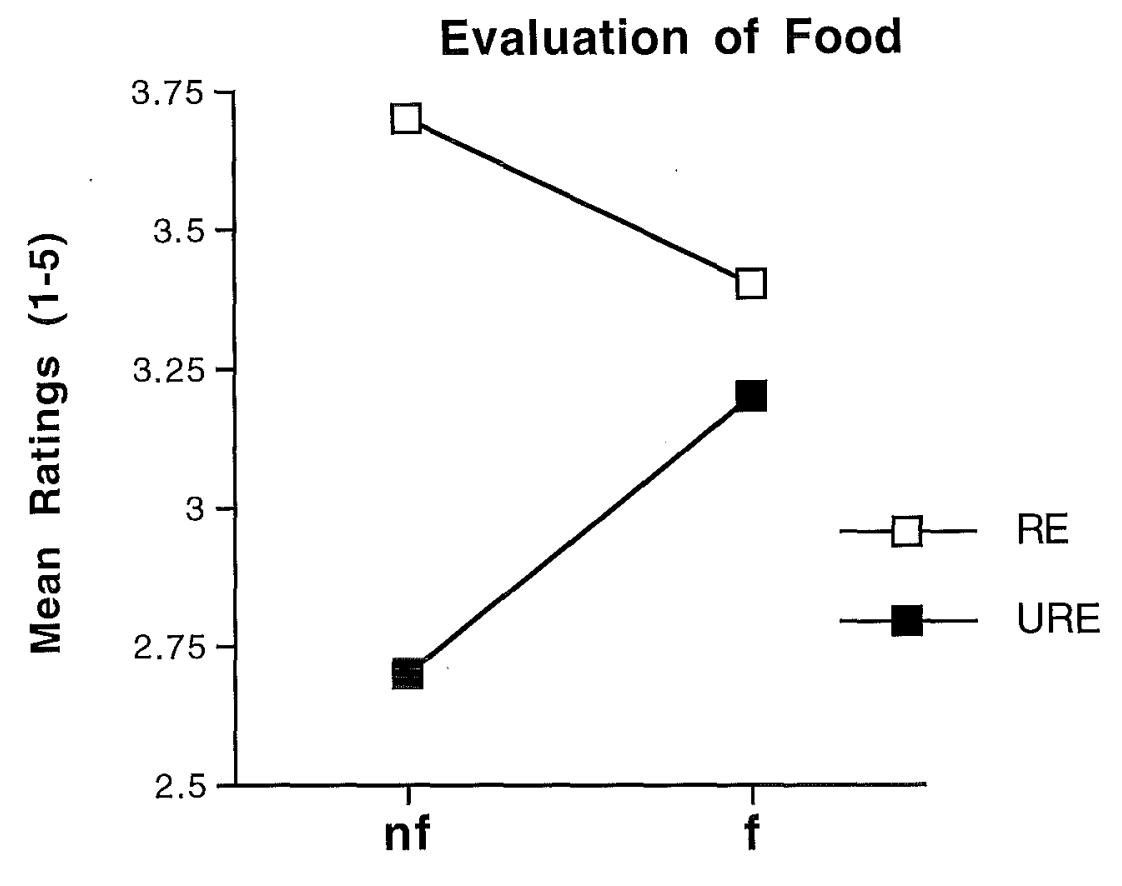

Condition

\section{Figure 4.}

Mean ratings on the dimension "Evaluation of Food" for Restrained (RE) and Unrestrained (URE) Eaters under Nonfasting (nf) and Fasting Conditions (f).

No significant results were found from the ANOVAs performed on "Desire for Food" and "Hunger for Food". The mean scores for groups across conditions for each dimensionalised subcategory are displayed in Table 7. 


\section{Self}

Analysis of each of the dimensionalised Self subcategories, "Physical state", "Evaluation of personality and behaviour", "Evaluation of body and appearance", "Emotional state" revealed only one significant result. An interaction effect was found for the subcategory "Evaluation of personality and behaviour" $[\mathrm{F}(1,16)=6.2, \mathrm{p}<.05]$. Unrestrained eaters' evaluations of their own personality and behaviour were significantly more negative on the fasting day $(\mathrm{M}=2.0, \mathrm{SD}=0.0$, "negative") than on the non-fasting day ( $\mathrm{M}=3.3, \mathrm{SD}=1.0$, "neutral") whereas restrained eaters' evaluations of their personality and behaviour on the fasting day $(\mathrm{M}=2.5, \mathrm{SD}=0.7)$ did not differ significantly from those made on the non-fasting day $(M=2.2, S D=0.3)$. Restrained eaters' evaluations of their own personality and behaviour $(\mathrm{M}=2.2, \mathrm{SD}=0.3)$ were however, significantly more negative than the unrestrained eaters $(M=3.3, S D=1.0)$ on the non-fasting day (See Figure 5). Overall, both groups across both conditions evaluated their personality and behaviour as negative - neutral.

\section{Self Evaluation: Personality and Behaviour}

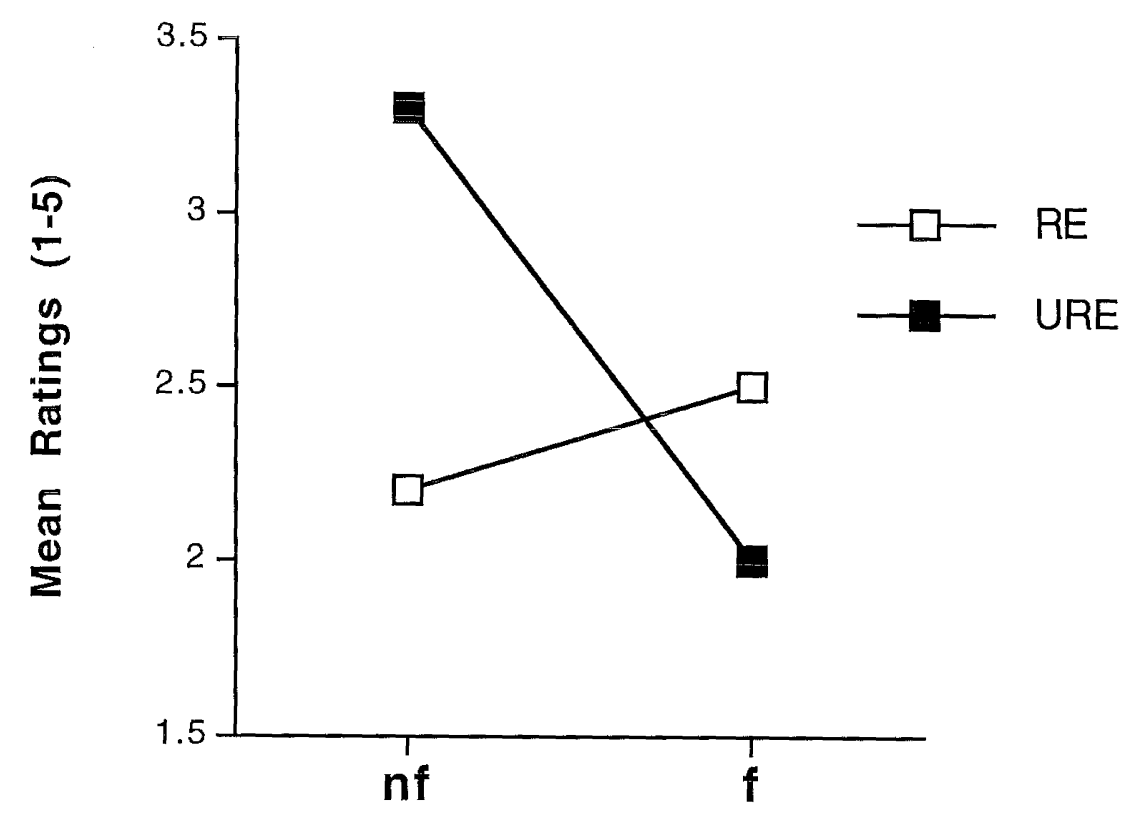

Condition

\section{Figure 5.}


The results from the ANOVAs of the self subcategories "Physical state", "Evaluation of own body and appearance", and "Emotional state" were not significant.

\section{Others}

None of the ANOVAs performed on the dimensionalised Others subcategories "Evaluation of others' personality and behaviour", "Evaluation of others' body and appearance", "Evaluation of self's personality and behaviour by others" yielded significant results. The subcategory "Evaluation of self's body and appearance" could not be analysed as only a very small proportion of thoughts were reported along this dimension $(\mathrm{N}=6)$. The mean scores for both groups across conditions are displayed in Table 7. 


\section{DISCUSSION}

Overall, the present study showed that there are few differences between restrained eaters and unrestrained eaters in the frequencies of their everyday cognitions about food and self, although a difference was found between the two groups in terms of their percentages of thoughts about others. There were, however, clear differences in the nature of the thoughts across the two groups. Unrestrained eaters evaluated their own personality and behaviour more negatively under the fasting condition than under the non-fasting condition whereas restrained eaters' evaluations did not differ across conditions. In addition, restrained eaters evaluations of their personality and behaviour were more negative than the unrestrained eaters under the non-fasting condition. Furthermore, restrained eaters valued food more highly than unrestrained eaters overall.

Both groups, independent of fasting condition, thought significantly more often about issues relating to themselves (self) followed by thoughts about food, other people and miscellaneous issues. The most frequent types of thoughts recorded about the self were associated with emotional states and planning. The majority of thoughts about food included food/eating planning thoughts, and observations about their own eating patterns and attitudes toward food. The highest percentage of thoughts about others were coded in the others-miscellaneous category.

This is the first study of its kind to have produced data on the spread of everyday cognitions across and within content areas. In a similar study, Zotter \& Crowther (1991) categorised in vivo cognitions in terms of two content areas : eating/weight-related or other issues. They found a smaller relative percentage of cognitions about eating/weightrelated issues $(7-11 \%)$ than the present study's twenty percent. Direct comparisons are difficult as Zotter \& Crowther's eating/weight category differs from the food category in the present study. However, because subjects in the present study were required to record their food intake they may have had a greater bias towards reporting thoughts about food than Zotter \& Crowther's subjects who did not record their food intake. 
It was proposed that the random signalling of the pager would increase the likelihood of naturally-occurring thoughts being reported because the subjects would not be able to anticipate the signal. Analyses of the transcripts suggested that this was largely successful although occasionally a few subjects reported thoughts about the pager and expectations of a signal. Thus, it appears that the methodology of this study created minimal interference in the production and reporting of naturally-occurring thoughts.

It should also be pointed out that the majority of subjects in the present study were either unemployed or students. Women who worked often were unwilling to participate in the study due to the amount of time and effort required and this may limit the generalisability of the results.

With respect to differences across fasting and non-fasting conditions the present study found that food deprivation was associated with an increase in the frequency of the total number of thoughts about food for both restrained and unrestrained eaters. This finding is partially consistent with predictions from Herman \& Polivy's (1984) boundary model of restraint which suggests that high levels of dietary restraint will place the organism outside the hunger-satiety boundaries, and the organism will seek food in order to restore physiological and psychological homeostasis. Herman \& Polivy's (1984) model, however, also predicts that unrestrained eaters will experience more discomfort than restrained eaters under fasting conditions as restrained eaters have wider hungersatiety boundaries than unrestrained eaters, however restrained and unrestrained eaters in the present study did not differ in terms of their total percentage of thoughts about food, or in terms of the intensity of their hunger levels or their desire for food, experienced under the fasting condition.

It is possible that differences in the intensity of hunger and desire for food may have been found if thoughts about hunger and desire for food had been analysed at different times of a day instead of averaged over a day. The same cautionary note may apply to the lack of differences between restrained and unrestrained eaters' average emotional and physical states under the fasting condition. 
The only indication that unrestrained eaters experienced more discomfort on the fasting day was that unrestrained eaters' evaluations of their own personalities and behaviours were more negative under the fasting condition than under the nonfasting condition. Similarly, unrestrained eaters' evaluations of their own personalities and behaviours were significantly more positive than those of restrained eaters under the nonfasting condition with the two groups being equally negative under the fasting condition. These results suggest that dietary restraint negatively influences individuals' self-concepts. This is the first study to have examined the effect of fasting on the nature of unrestrained or restrained eaters' self-concepts.

Finally, restrained eaters were found to have significantly more thoughts about others under the fasting condition than under the nonfasting condition whereas unrestrained eaters did not differ across conditions. The theoretical significance (if any) of this result is unclear as the increase in the restrained eaters' thoughts about others did not correspond to a significant decrease in the percentage of thoughts about self or food. There were no other significant results obtained from analyses of the Others subcategories and no previous study has explored restrained and unrestrained eaters' thoughts about others.

The main focus of the present study was to identify general differences between restrained and unrestrained eaters. Overall, restrained and unrestrained eaters did not differ in their relative percentages of thoughts about food in total and their relative percentages of thoughts about the food subcategories : hunger, desire for food, food-planning, evaluation of food, and miscellaneous issues related to food. This finding is consistent with studies that have employed thought-sampling (Zotter \& Crowther, 1991), think-aloud techniques (Jansen et al., 1988) and repertory grids (Butow et al., 1993). The only study that has found a difference between restrained and unrestrained eaters in the percentage of thoughts about food-related issues is King et al.'s (1991) study which employed recall and descriptive tasks and found that restrained eaters have a greater bias to recall food-related thoughts. It appears, therefore, that restrained and unrestrained eaters do not differ in their relative frequencies of food thoughts unless these thoughts are primed. 
Whereas there were no differences between restrained and unrestrained eaters in the frequency of their thoughts about food, analyses of the nature of their cognitions revealed that restrained eaters evaluated food more highly than unrestrained eaters overall. This result is consistent with Herman \& Polivy's hypothesis that food restriction increases an organisms motivation to seek food. The only other study that has explored restrained and unrestrained eaters evaluations of food have not found restrained and unrestrained eaters to differ in the nature of their descriptions of food (Butow et al., 1993). However, it is probable that Butow et al.'s study measured a different aspect of cognition than the present study. Their study required subjects to complete repertory grids whereas the present study measured in vivo cognitions.

In the present study restrained and unrestrained eaters did not differ in terms of the intensity of their average hunger states and desire-for-food ratings. By contrast, Ogden \& Wardle (1991) found that high restraint subjects reported significantly higher hunger ratings compared to controls. However, in Ogden \& Wardle's study the hunger ratings were measured retrospectively following a disinhibitory challenge whereas the hunger ratings in the present study were the average hunger levels of the subjects over each day. Again, it is possible that differences between groups in hunger states may have occurred at different times of the day in the present study and that these differences were subsumed by the average score for the day.

Restrained and unrestrained eaters did not differ in their relative percentage of thoughts about themselves yet differed in the nature of some of these thoughts. Restrained eaters' in vivo cognitions indicated a more negative self-concept in terms of their own personality and behaviours than unrestrained eaters under normal (nonfasting) conditions. The present study did not find a difference in the nature of restrained and unrestrained eaters in vivo evaluations of their own bodies and appearance, however, the results of the EDI indicated that the restrained eaters had a higher drive to be thin and experienced greater body dissatisfaction than the 
unrestrained eaters. These findings are consistent with the results of other studies in that studies that have examined self-concepts using self-report questionnaires have found restrained eaters exhibit lower levels of self-acceptance and more negative selfconcepts about their personal and physical attributes than controls (e.g. Dykens \& Gerrard, 1985) whereas studies examining in vivo cognitions have found no difference between restrained and unrestrained eaters in terms of the frequencies of negative cognitions regarding their weight and an appearance (e.g. Cooper \& Fairburn, 1992). Thus it appears that self-questionnaires and in vivo techniques differ in the cognitive constructs they are accessing and measuring.

The results of the BDI revealed that restrained eaters had significantly higher scores than the unrestrained eaters indicating that the restrained eaters had higher depressive symptomatology. Both groups were, however, within the "none-minimal depression" range of the BDI. No differences were found in the emotional tone of in vivo cognitions of restrained and unrestrained eaters. Other studies that have employed naturalistic measures of cognitions (Zotter \& Crowther, 1991; Cooper \& Fairburn, 1992) have similarly found no differences in the affective tone of restrained and unrestrained eaters' cognitions whereas studies which have used self-report questionnaires have found that restrained eaters report more depressogenic cognitions than unrestrained eaters (Ogden \& Wardle, 1991; Dykens \& Gerrard, 1985). Overall, however the results of the present study support the view that there are no major differences between restrained and unrestrained eaters in terms of the emotional tone of their cognitions. These findings further highlight the discrepancy that exists between naturalistic measures of cognition and self-report questionnaires. 


\subsection{Conclusions and Recommendations for Future Research}

The majority of significant differences in the everyday cognitions of restrained and unrestrained eaters in the present study were in respect to the nature of their cognitions. Differences in the frequencies of restrained and unrestrained eaters' thoughts were seldom found in the present study and in similar studies which have measured in vivo or spontaneous cognitions. These findings contrast with the results of studies that have employed self-report questionnaires and hence call into question the validity of the extensive use of self-report questionnaires to obtain information about the cognitions of women with eating disorders. It is important that future research identify the types of cognitive phenomena being accessed by these different techniques in order to increase the accuracy of cognitive theories and maximise the efficacy of the cognitive treatment of eating disorders.

The results from this study provide important information for further development of the continuum hypothesis (e.g. Ruderman, 1986a) by indicating that it is the nature of cognitions, not the frequency of these cognitions that differentiate the everyday cognitions of restrained eaters from those of unrestrained eaters. It is probable therefore that the cognitions of restrained eaters and those of women with eating disorders are related in terms of the nature of their thoughts about food and themselves rather than by a mere preoccupation (increase in the frequency of thoughts) with food and weight-related issues. It is suggested that future research focus on identifying similarities in the nature of cognitions of restrained eaters and individuals with eating disorders, particularly cognitions regarding attitudes toward food and self. 


\section{REFERENCES}

Beck, A.T., Rush, A.J, Shaw, B.F., \& Emery, G. (1979). Cognitive therapy of depression. New York : Guilford Press.

Beck., A.T., \& Steer, R.A. (1987). Beck Depression Inventory Manual. San Antonio : The Psychological Corporation Harcourt Brace Jovanovich, Inc.

Blackwell, R.T., Galassi, J.P., Galassi, M.D., \& Watson, T.E. (1985). Are Cognitive Assessment Methods Equal? A Comparison of Think Aloud and Thought Listing. Cognitive Therapy and Research, 9, $399-413$.

Brownell, K.D. (1991). Dieting and the search for the perfect body : Where physiology and culture collide. Behavior Therapy, 22, 1 - 12.

Bulik, C. (1992). Bulimia Treatment Study Cognitive Therapy Manual. Christchurch, N.Z.

Butow, P., Beaumont, P., \& Touyz, S.W. (1993). Cognitive processes in dieting disorders. International Journal of Eating Disorders, 14, 319 - 329.

Clark, D.A. (1988). The Validity of Measures of Cognitions : A Review of the Literature. Cognitive Therapy and Research, 12, $1-20$.

Clark, D.A., Feldman, J., \& Channon, S. (1989). Dysfunctional Thinking in Anorexia and Bulimia Nervosa. Cognitive Therapy and Research. 13, $377-387$.

Cooper, M.J., \& Fairburn, C.G. (1992). Thoughts about eating, weight and shape in anorexia nervosa and bulimia nervosa. Behaviour Research and Therapy, 30, $501-511$.

Cooper, M.J., Clark, D.M., \& Fairburn, C.G. (1993). An experimental study of the relationship between thoughts and eating behaviour in bulimia nervosa. Behaviour Research and Therapy, 31 , $749-757$.

Crutcher, R.J. (1994) Telling What We Know : The Use of Verbal Report Methodologies in Psychological Research. Psychological Science, 5, 241- 244.

Davison, G.C., Robins, C. \& Johnson, M.K. (1983). Articulated Thoughts During Simulated Situations : A Paradigm for Studying Cognition in Emotion and Behaviour. Cognitive Therapy and Research, 7, $17-40$. 
Dewberry, C., \& Ussher, J.M. (1994). Restraint and Perception of Body Weight Among British Adults. The Journal of Social Psychology, 134, $609-610$.

Dwyer, J.T., Feldman, J.I., \& Mayer, J. (1967). Adolescent dieters : Who are they? American Journal of Clinical Nutrition, 20, 1045 - 1056.

Dykens, E.M., \& Gerrard, M. (1986). Psychological Profiles of Purging Bulimic, Repeat Dieters, and Controls. Journal of Consulting and Clinical Psychology, 54, 283 - 288.

Eldredge, K., Wiilson, G.T., \& Whaley, A. (1990). Failure, self-evaluation, and feeling fat in women. International Journal of Eating Disorders, 9, 37 - 50.

Ericsson, K.A., \& Simon, H.A. (1980). Verbal reports as data. Psychological Reviews, 87, 215 - 251.

Fairburn, C.G. (1985). Cognitive-behavioural treatment for bulimia. In D.M. Garner \& P.E. Garfinkel (Eds.), Handbook of psychotherapy for anorexia and bulimia (pp.160 - 192). New York : Guilford Press.

Fairburn, C.G., Cooper, P.J., Cooper, M.J., McKenna, F.P., \& Anastasiades, P. (1991). Selective Information Processing in Bulimia Nervosa. International Journal of Eating Disorders, 10, 415 422.

French, S.A. (1992). Restraint, Food Choice, and Cognitions. Addictive Behaviors, 17, 273 - 281.

Garner, D.M. (1991) Eating Disorder Inventory-2 : Professional Manual. Odessa, Florida : Psychological Assessment Resources, Inc.

Garner, D.M., \& Olmsted, M.P. (1984). The Eating Disorder Inventory Manual. Odessa, Florida : Psychological Assessment Resources.

Glaser, B., \& Strauss, A.L. (1967). The discovery of grounded theory : Strategies for qualitative research. Chicago: Aldine Publishing Co.

Glaser, B.G., \& Strauss, A.L. (1969). The Discovery of Grounded Theory : Strategies for Qualitative Research. New York : Aldine

Goldberg, J.O., \& Shaw, B.F. (1989). The Measurement of Cognition in Psychopathology. Clinical and Research Applications. In A. Freeman (Ed.), Manual of Cognitive-Behavioral Interventions. New York : Plenum Press. 
Heatherton, T.F., \& Polivy, J. (1992). Chronic Dieting and Eating Disorders : A Spiral Model. In J.H. Crowther, D.L. Tennenbaum, S.E. Hobfoll, \& M.A. Parris Stephens (Eds.), The Etiology of Bulimia Nervosa : The Individual and Familial Contest, Chapter 8, 133 - 155. Washington : Hemisphere Publishing Corporation.

Heatherton, T.F., Herman, C.P., Polivy, J. King, G.A., \& McGree, S.T. (1988). The (mis) measurement of restraint : An analysis of conceptual and psychometric issues. Journal of Abnormal Psychology. 97, $19-28$.

Heimberg, R.G., Nyman, D., \& O'Brien, G.T. (1987). Assessing Variations of Thought-Listing Technique : Effects of Instructions, Stimulus Intensity, Stimulus Modality, and Scoring Procedures. Cognitive Therapy and Research, 11, $13-24$.

Herman, C.P., \& Mack, D. (1975). Restrained and unrestrained eating. Journal of Personality, 43, 645 $-660$.

Herman, C.P., \& Polivy, J. (1980). Restrained eating. In A.J. Stunkard (Ed.), Obesity (pp. 208 - 225). Philadelphia : Saunders.

Herman, C.P., \& Polivy, J. (1984). A Boundary Model for the Regulation of Eating. In A.J. Stunkard, \& E. Stellar (Eds.), Eating and Its Disorders, pp. 141 - 156. New York : Raven Press.

Herman, C.P., Polivy, J., Pliner, P \& Threikeid, J. (1978). Distractibility in dieters and nondieters : an alternative view of "externality". Journal of Personality and Social Psychology , 36, 536 - 548.

Hurlburt, R.T. (1979). Random sampling of cognitions and behavior. Journal of Research in Personality, 13, $103-111$.

Hurlburt, R.T. (1980). Validation and correlation of thought-sampling with retrospective measures. Cognitive Therapy and Research, 4, 235 - 238.

Jansen, A., Merckelbach, H., Oosterlaan, J., Tuiten, A., \& van den Hout, M. (1988). Cognitions and Self-talk During Food Intake of Restrained and Unrestrained Eaters. Behavior Research and Therapy, 5. $393-398$.

King, G.A., Polivy, J., \& Herman, C.P. (1991). Cognitive aspects of dietary restraint : Effects on person memory. International Journal of Eating Disorders, 10, 313 - 321 . 
Klinger, E. (1978). Modes of Normal Conscious Flow. In K.S. Pope \& J.L. Singer (Eds.), The Stream of Consciousness. Scientific Investigations into the Flow of Human Experience, Chapter 8, pp 225 - 258. New York : Plenum Press.

Lacy, J.H., Coker, S., \& Birtchnell, S.A. (1986). Bulimia : Factors associated with its etiology and maintenance. International Journal of Eating Disorders, 5, 475 - 487.

Leon, G.R., Perry, C.L., Mangelsdorf, C., \& Tell, G.J. (1989). Adolescent nutritional and psychological patterns and risk of the development of an eating disorder. Journal of Youth and Adolescence, 18, 273 - 282.

Merluzzi, T.V., \& Boltwood, M.D. (197?). Cognitive Assessment (p. 249 - 266). In A. Freeman (Ed.), Manual of Cognitive-Behavioral Interventions. New York : Plenum Press.

Mitchell, J.E., Hatsukami, D., Eckert, E.D., \& Pyle, R.L. (1985). Characteristics of 275 patients with bulimia. American Journal of Psychiatry 142, 482 - 485.

Morris, P. (1981). The cognitive psychology of self-reports. In C. Antaki (Ed.). The psychology of ordinary explanations of social behaviour. London : Academic Press.

Nisbett, R.E., \& Wilson, T.P. (1977). Telling more than we can know : Verbal reports on mental processes. Psychological Review, 84, $231-259$.

Nylander (1971). The feeling of being fat and dieting in a school population. Acta Socio-Medica Scandinavica, 1, 17 - 26).

Ogden, J., \& Wardle, J. (1991) Cognitive and emotional responses to food. International Journal of Eating Disorders, 10, 297 - 311.

Polivy, J., \& Herman, C.P. (1985). Dieting and bingeing. A causal analysis. American Psychologist, 40, $193-201$.

Polivy, J., \& Herman, C.P. (1987), Diagnosis and Treatment of normal eating. Journal of Consulting and Clinical Psychology, 55, $635-644$.

Polivy, J., \& Herman, C.P. (1992). Undieting: A program to help people stop dieting. International Journal of Eating Disorders, 11, 261 - 268.

Polivy, J., Heatherton, T.F., \& Herman, C.P. (1988) Self-Esteem, Restraint, and Eating Behavior. Journal of Abnormal Psychology 97, 354 - 356. 
Poulakis, Z. \& Wertheim, E.H. (1993). Relationships Among Dysfunctional Cognitions, Depressive Symptoms, and Bulimic Tendencies. Cognitive Therapy and Research, 17, 549 - 559.

Rand, C.S.W., \& Kuldau, J.M. (1991). Restrained Eating (Weight Concerns) in the General Population and Among Students. International Journal of Eating Disorders, 10, 699 - 708.

Rennie, D.L., Phillips, J.R., \& Quartaro, G.K. (1988). Grounded Theory : A promising approach to conceptualisation in psychology? Canadian Psychology, 29, 139 - 150.

Rosen, J.C., \& Gross, J. (1987). Prevalence of weight reducing and weight gaining in adolescent girls and boys. Health Psychology, 6, $131-147$.

Ruderman, A.J. (1985). Restraint and irrational cognitions, Behavior Research and Therapy, 23, 557 561.

Ruderman, A.J. (1986a) Bulimia and irrational beliefs. Behaviour Research and Therapy, 24, 193 - 197.

Ruderman, A.J. (1986b). Dietary Restraint : A Theoretical and Empirical Review. Psychological Bulletin. 99, $247-262$.

Serdula, M.K., Williamson, D.F., Anda, A.D., Levy, A., Heaton, A., \& Byers, T. (1994). Weight Control Practices in Adults : Results of a Multistate Telephone Survey. American Journal of Public Health, 84, $1821-1824$.

Sobal, J. (1995). Social Influences on Body Weight. In K.D. Brownell \& C.G. Fairburn (Eds.), Eating Disorders and Obesity: A Comprehensive Handbook. Chapter 14, pp. 73 - 77. New York : The Guilford Press.

Steiger, H., Goldstein, C., Mongrain, M., \& Van der Feen, J. (1990). Description of Eating-disordered, Psychiatric, and Normal Women Along Cognitive and Psychodynamic Dimensions. International Journal of Eating Disorders, 9, 129 - 140.

Strauss, A., \& Corbin, J. (1990). Basics of Qualitative Research: Grounded Theory Procedures and Techniques. Newbury Park : Sage Publications.

Thompson, D.A., Berg, K. M., \& Shatford, L.A. (1987). The heterogeneity of bulimic symptomatology : Cognitive and behavioural dimensions. International Journal of Eating Disorders. 6, $215-234$. 
van Strien, T., Frijters, J.E., Bergars, G.P.A., \& Defars, P.C. (1985). The Dutch Eating Behaviour Questionnaire (DEBQ) for assessment of restrained, emotional and external eating. International Journal of Eating Disorders, 5, 295 - 315.

Ward, T., Louden, K., Hudson, S.M., \& Marshall, W.L. (1996). A Descriptive Model of the Offence Chain for Child Molesters. Journal of Interpersonal Violence, 10, 4, 452 - 472.

Westenhoefer, J. (1991). Dietary Restraint and Disinhibition : Is Restraint a Homogeneous Construct? Appetitie. 13, $45-55$.

Wilfley, D.E., \& Rodin, J. (1995). Cultural Influences on Eating Disorders. In K.D. Brownell \& C.G. Fairburn (Eds.), Eating Disorders and Obesity: A Comprehensive Handbook, Chapter 15, pp. 78 82. New York: The Guilford Press.

Wooley, S.C., \& Wooley, O.W. (1985). Intensive outpatient and residential treatment for bulimia. In D.M, Garner \& P.E. Garfinkel (Eds.), Handbook of psychotherapy for anorexia nervosa and bulimia (pp. 391 - 430). New York: Guilford Press.

Zotter, D.L., \& Crowther, J.H. (1991). The role of cognitions in bulimia nervosa. Cognitive Therapy and Research, 15, $413-426$. 


\section{APPENDIX A}

The Restraint Scale (Herman \& Mack, 1975)

1. How often are you dieting?

(never; rarely; sometimes; usually; always) (score : 0 - 4)

2. What is your maximum weight gain within a week? (score : 1pt/3lbs)

3. Do you eat sensibly before others and make up for it alone? (never; rarely; often; always) (score : 0 - 3)

4. Do you give too much time and thought to food? (never; rarely; often; always) (score : 0 - 3)

5. Do you have feelings of guilt after overeating? (never; rarely; often; always) (score : 0 - 3). 
APPENDIX B

\section{INSTRUCTIONS FOR KEEPING A DIET RECORD}

\section{PLEASE READ THESE IMPORTANT INSTRUCTIONS CAREFULLY}

" Please record ALI food and drinks consumed

* Pleasc record the food at the time of eating and NOT from memory at the end of the day

* You should include all meals \& snacks, plus sweets, drinks (including water) etc.

* Remember to include any additions to foods already tecorded such as: sauces, dressings or exiras e.g. gravy, salad dressings, stuffings sugar, honey, syrups etc., butter or margariate (e.g. added to bread; crackers, vegetables).

*If you do not eat a particular meal or snack, simply draw a line across the page at this point. This will show that you definitely have not caten anything.

\section{DESCRIBLNG FOOD AND DRINK - GUTDELINES}

1. Please give details of the method of cooking all foods (e.g. fried, grilled, boiled, roasted, steamed, poached, stewed.)

2. Give as many details as possible about the type of food that you eat
e.g. brand name of food where applicable
(e.g. Miracle margarine)
type of: breakfast cereal (e.g. Weetbix)
milk (e.g. whole milk or 'trim milk')
cake or biscuit (e.g. fruit cake, wheatmeal biscuit)
fruit (e.g. fresh, canned, dried, stewed)
sofi drink (e.g. regular or low calorie).

3. Name the type of cheese, tish or meat (e.g. cheddar, cod Elliet, loin of pork)

e.g. EOGS

Are they Eried, boiled, poached or scrambled?

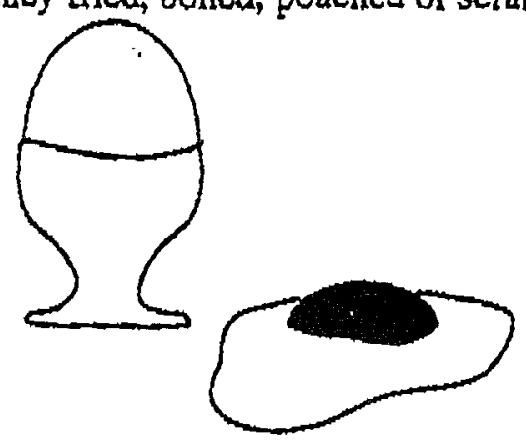




\section{APPENDIX B continues}

\section{RECORDING THE AMOUNTS OF FOODS YOU EAT}

It is also very imponant to record the quantity of each lood and drink you consume.

Here are some suggestions on how to record amounts:

- IN HOUSEHOLD MEASUREMENTS

For many foods such as vegetables, cereals and canned or stewed fruit, a househoid measurement is adequate.

e.g. STATE THE NUMBER OF TEASPOONS ( $($ ), TABLESPOONS (T), CUPS etc. State whether spoons are level, rounded or heaped.

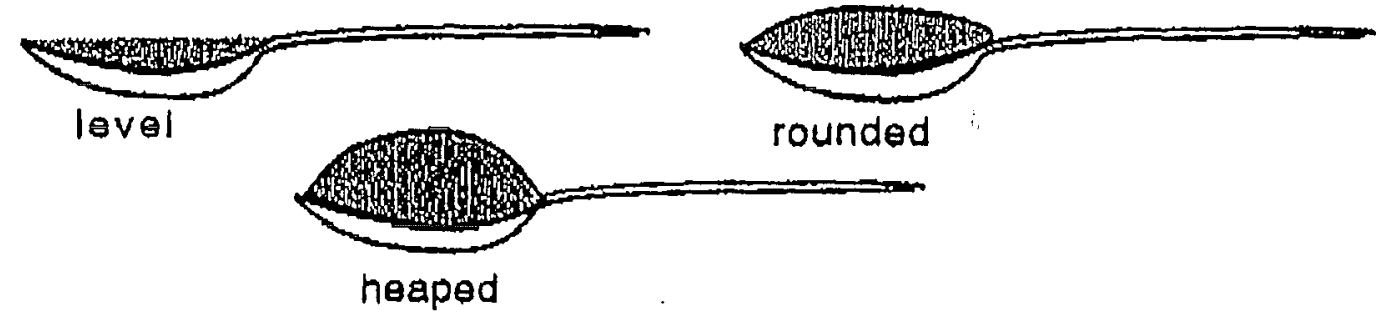

Butter \& margarine can be measured in teaspoons or tablespoons if you find this an easy method.

- WEIGHTS MARKED ON PACKAGES

All convenience foods have their weight marked on the packaging and this can be quoted. e.g. half a $425 \mathrm{~g}$ can of baked beans.

- BREAD - indicate the size of the slices (e.g. sandwich, medium, tonster).

- CHEESE, MEAT \& FISH

If at all possible, it would be very helpful to weigh your portions of these foods.

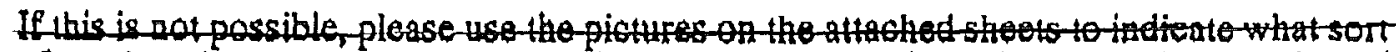

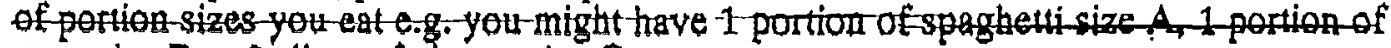
meatsize-B or 2 slices of cheoso-sizoc.

- USE COMPARISONS for describing portion sizes where this is easier e.g. potato * size of a hens' egg, cheese - size of a matchbox.

IT IS VERY IMPORTANT THAT YOU DO NOT ADJUST WHAT YOU EAT AND DRINK BECAUSE YOU ARE KEEPING A RECORD. THIS IS VERY EASY TO DO, BUT REMEMBER, WE ARE INTERESTED IN YOUR EATING HABITS, NOT THE PERFECT DIET!!! 


\section{APPENDIX C}

\section{Cognitive Self-monitoring Training Session}

\section{Behaviours}

Behaviours are observable actions- the things you do. Behaviours include things such as walking, talking, driving, shopping, visiting friends, changing clothes and so on.

\section{Thoughts}

Thoughts are things that go on in your head. They may be statements that you say to yourself, or they may be pictures or visual images you see in your imagination. For example, you might have a picture in your mind of palm trees, golden sands, blue seas, or you might say to yourself "Wouldn't it be great to be lying on a beach on a tropical island"- they are both thoughts.

Our minds are rarely blank and there are thousands of thoughts that go unexamined each day. It's like there is a running commentary happening all the time in our heads. You may not be aware of many of your thoughts unless you focus your attention on them, but they are there nonetheless. When you see a women riding a bicycle, you may think "She's riding fast", or "She should be wearing a helmet" or "She looks thin" or "I like her shorts" or "She had better be careful, there's a car pulling out in front of her", or "l like her shorts," or "l'd never be able to ride a bike wearing shorts like that - I'm to fat", or "She looks like my cousin, Ann" or many other possibilities. These are all thoughts. Different people would have different thoughts in response to the same situation. The same person might have different thoughts depending on how she is feeling at the time.

\section{Feelings}

Feelings are emotions. Unlike thoughts, feelings cannot be identified by little sentences or images in our brains. Sometimes they are harder to identify. You may need to sit quietly, turn your attention inward, and sense how you feel.

Some people have difficulty identifying certain feelings. In some families, for example, it is forbidden to express negative emotions such as anger or rage. It does not mean that these feelings do not exist, rather that they may be more difficult to identify 


\section{APPENDIX D}

\section{Instructions for the Fasting Day}

\section{Begin fasting at $6 \mathrm{pm}$ on the arranged date.}

2. Your first "beep" will be at 8.30am the following morning.

3. You will be paged approximately every forty minutes from $8.30 \mathrm{am}$ until 10pm.

4. Record your thoughts by speaking into the tape as soon as you are paged. The thoughts you record should be the thoughts you were thinking immediately before the pager went off. Please record your thoughts in private - not in front of others (they may distract you).

5. At $6 \mathrm{pm}$ please eat the meal provided, in private also if possible. As well as continuing to record your thoughts when you are paged please record your thoughts just before you eat, while you are eating, and after you have had the meal provided. Also remember to note the type and amount of food and drinks you have up until you go to bed.

Note : You are free to eat what you want after you have completed the provided meal but remember to record what you eat.

\section{Make your last thoughts recording just before you go to sleep.}

Note : Please do not miss out any recordings. If you are unable to record your thoughts at the time of the beep, jot down the time and your thoughts on a piece of paper and record your thoughts on the tape as soon as possible. 


\section{APPENDIX D continues}

\section{Instructions for Non-fasting day}

1. Begin recording all food and drink you intake from $6 \mathrm{pm}$ on the date arranged. Remember to record the type, brand, amount and the method of cooking (e.g a heaped tablespoon of Watties frozen peas, boiled). Continue to record your food and drink intake until you go to bed tomorrow night.

2. Your first "beep" will be at 8.30 am the following morning.

3. You will be paged approximately every forty minutes from $8.30 \mathrm{am}$ until $10 \mathrm{pm}$.

4. Record your thoughts by speaking into the tape as soon as you are paged. The thoughts you record should be the thoughts you were thinking immediately before the pager went off. Please record your thoughts in private - not in front of others (they may put you off).

5. At $6 \mathrm{pm}$ please eat the meal provided, in private also if possible. As well as continuing to record your thoughts when you are paged up until 10pm please record your thoughts just before you eat, while you are eating, and after you have had the meal provided. Also remember to note the type and amount of food and drinks you have up until you go to bed.

Note : You are free to eat what you want after you have completed the provided meal but remember to record what you eat.

6. Make your last thoughts recording just before you go to sleep.

Note : Please do not miss out any recordings. If you are unable to record your thoughts at the time of the beep, jot down the time and your thoughts on a piece of paper and record your thoughts on the tape as soon as possible. 